NBER WORKING PAPER SERIES

\title{
THE STRATEGIC TIMING INCENTIVES OF COMMERCIAL RADIO STATIONS: AN EMPIRICAL ANALYSIS USING MULTIPLE EQUILIBRIA
}

\author{
Andrew Sweeting \\ Working Paper 14506 \\ http://www.nber.org/papers/w14506 \\ NATIONAL BUREAU OF ECONOMIC RESEARCH \\ 1050 Massachusetts Avenue \\ Cambridge, MA 02138 \\ November 2008
}

This paper is a revised version of chapter 2 of my MIT Ph.D. thesis. I thank Glenn Ellison, Paul Joskow, Aviv Nevo, Rob Porter, Whitney Newey, Pat Bajari, Liran Einav, Brian McManus, Paul Ellickson and participants at numerous academic conferences, seminars and the 2003 National Association of Broadcasters/Broadcast Education Association Convention in Las Vegas for useful comments. I also thank Rich Meyer of Mediabase 24/7 for providing access to the airplay data and the National Association of Broadcasters for providing a research grant for the purchase of the BIAfn MediaAccess Pro database including the Arbitron share data. The paper has been much improved by the thoughtful insights of the coeditor and two referees. The previous title of this paper was "Coordination Games, Multiple Equilibria and the Timing of Radio Commercials". All views expressed in this paper, and any errors, are my own. The views expressed herein are those of the author(s) and do not necessarily reflect the views of the National Bureau of Economic Research.

NBER working papers are circulated for discussion and comment purposes. They have not been peerreviewed or been subject to the review by the NBER Board of Directors that accompanies official NBER publications.

(C) 2008 by Andrew Sweeting. All rights reserved. Short sections of text, not to exceed two paragraphs, may be quoted without explicit permission provided that full credit, including $\odot$ notice, is given to the source. 
The Strategic Timing Incentives of Commercial Radio Stations: An Empirical Analysis Using Multiple Equilibria

Andrew Sweeting

NBER Working Paper No. 14506

November 2008

JEL No. C35,C72,L13,L82

\begin{abstract}
Commercial radio stations and advertisers have potentially conflicting interests about when commercial breaks should be played. This paper estimates an incomplete information timing game to examine stations' equilibrium timing incentives. It shows how identification can be aided by the existence of multiple equilibria when appropriate data are available. It finds that stations want to play their commercials at the same time, suggesting that mechanisms exist which align the incentives of stations with the interests of advertisers. It also shows that coordination incentives are much stronger during drivetime hours, when more listeners switch stations, and in smaller markets.
\end{abstract}

\author{
Andrew Sweeting \\ Department of Economics \\ 213 Social Sciences \\ Box 90097 \\ Duke University \\ Durham, NC 27708 \\ and NBER \\ atsweet@duke.edu
}


"Unfortunately for advertisers, not every broadcaster runs commercial blocks at exactly the same time. Therefore, the flipper hell-bent on commercial avoidance can always find an escape route. Broadcasters cooperating with each other to standardize commercial pod timing can cut off all flipper escape routes. Imagine the poor flipper; wherever he turns, horrors . . . a commercial! Once the flipper learns that there is no escape, he will capitulate and watch the advertising." (Gross (1988))

\section{Introduction}

This paper estimates the strategic incentives of commercial radio stations deciding when to play their commercial breaks. The question of whether stations want to play their breaks at the same time (coordinate) or at different times (differentiate) is interesting because, while advertisers would almost certainly like stations to play their commercials at the same time, stations may not want to do so. My empirical results, which show that in equilibrium stations do want to coordinate, indicate that mechanisms exist which at least partially align stations' incentives with the interests of advertisers.

Broadcast radio and television stations sell commercial time to advertisers and attract consumers by bundling commercials together with different types of programming. The ability of consumers to try to avoid commercials by switching stations in search of non-commercial programming presents a challenge to this business model and the evidence suggests that switching is quantitatively important. For example, Abernethy (1991) estimates that in-car listeners switch stations 29 times per hour on average and Dick and McDowell (2003) find that in-car listeners avoid more than half the commercials they would hear if they never switched stations. The above quotation argues that switching can be rendered ineffective if stations air commercials simultaneously. However, while advertisers would like stations to reduce commercial avoidance ${ }^{1}$, stations may have rather different incentives because a station's revenues from airing a commercial are not directly related to how many people listen to it. Instead, Arbitron, the radio ratings company, only reports estimates of a station's average audience and this may be maximized by playing commercials at different times to other stations.

A simple model captures these different incentives. Suppose that there are two commercial stations (A and B) and an outside option for listeners which never has commercial programming (e.g., NPR

\footnotetext{
${ }^{1}$ Brydon (1994) argues that "for advertisers, the key point is this: if, at the touch of a button, you can continue to listen to that [music] for which you tuned in, why should you listen to something which is imposing itself upon you, namely a commercial break" and he suggests that stations should "transmit breaks at universally agreed uniform times. Why tune to other stations if it's certain that they will be broadcasting commercials as well?".
} 
or a CD). There are two units of listeners. One unit has A as its preferred station (the "P1" in radio jargon) and one unit prefers $B$. There is an infinite sequence of odd and even time periods and each station has to choose between playing commercials in even periods or odd periods, playing music in the remainder. Listeners listen to their preferred station when it is playing music. When it plays commercials a proportion $\theta$ of these listeners switch to the other commercial station if it is playing music. If the other station also has commercials then $\theta^{\prime}$ of listeners will switch to the outside option. If stations play commercials at the same time then the average audience of a commercial will be $1-\theta^{\prime}$ and a station's average audience will be $\frac{2-\theta^{\prime}}{2}$. On the other hand, if they play commercials at different times then these audiences will be $1-\theta$ and 1 respectively, as a lower audience during a commercial is offset by a higher audience when the other station has a break. If $\theta>\theta^{\prime}$, which is reasonable if commercial stations are closer substitutes with each other than with the outside option, then advertisers will want stations to play commercials at the same time while stations will not.

Of course, one might expect that the market would find ways to align incentives. ${ }^{2}$ For example, equilibrium prices should reflect the true value of commercials to advertisers. However, any individual station has only weak incentives to increase this value if its own commercial audience is not measured. This is particularly true because, even after recent reforms, the radio industry is still quite fragmented. For example, in Spring 2008 the Chicago market had 37 commercial stations with 15 different owners. ${ }^{3}$ Alternatively, advertisers may be able to measure the impact of their commercials even if they cannot measure their audience. For example, retailers can see how product demand responds to running commercials on a particular station or how many people respond when a commercial encourages them to "call now". Even if this response does not affect the revenues of the commercial in question, stations will care about it if it affects advertisers' willingness to pay for future spots.

I estimate stations' incentives using panel data on the timing of commercial breaks by 1,091 music stations in 144 radio markets in 2001. The data is extracted from airplay logs which record, on a minute-by-minute basis, the music which stations play. Figure 1 shows the average proportion of

\footnotetext{
${ }^{2}$ One might expect that advertisers would specify that commercials have to run at particular times to try to enforce coordination. While contracts do sometimes specify the hour in which the commercials will run, exact times are not specified presumably because it is very difficult for a station to guarantee a precise airing time in advance. I allow this type of noise to play an important role in the game which I set out below.

${ }^{3}$ Based on stations with enough listeners to be rated by Arbitron. Information taken from Radio and Records website (www.radioandrecords.com).
} 
Figure 1: Timing Patterns for Commercials Across 144 Markets
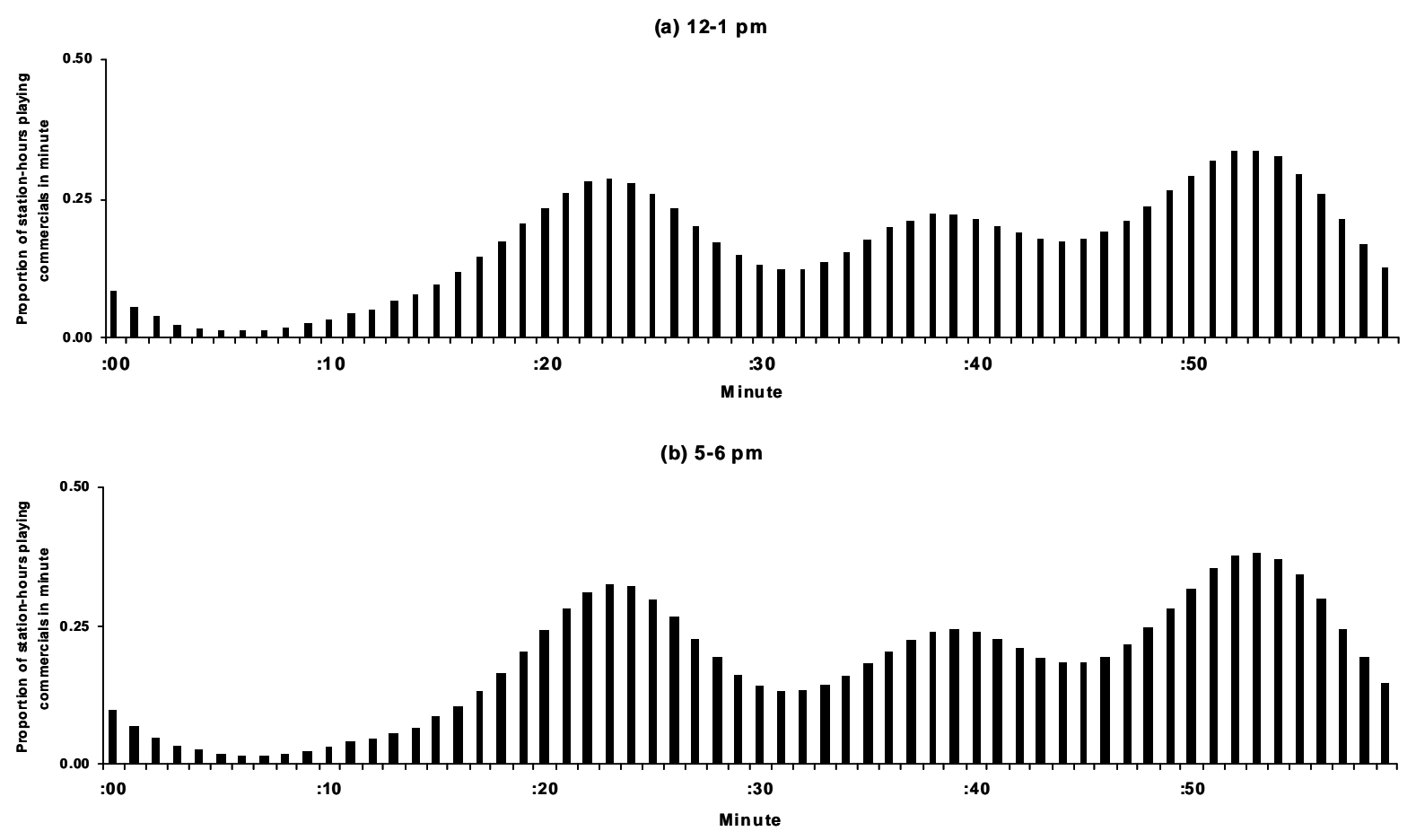

stations playing commercials in each minute during two different hours of the day.

The distributions are far from uniform indicating that stations tend to play commercials at the same time. However, we cannot infer from these aggregate patterns alone that stations want to coordinate on timing because it could also be explained by "common factors" making some parts of each hour particularly bad for commercials. Knowledge of the industry shows that common factors do affect timing decisions. For example, Arbitron estimates audiences based on how many people report listening to a station for at least five minutes during a quarter-hour (e.g. 4:30-4:45). Listeners who can be kept listening for ten minutes over a quarter-hour are therefore likely to count for two quarter-hours so stations avoid playing commercials, which would drive away listeners, at these times. They also avoid playing them at the beginning of each hour as many listeners switch on then and they are likely to switch stations immediately if they tune-in during a commercial.

How can strategic incentives be identified if these types of common factor are important? One approach would be to make exclusion restrictions and exploit variation in the characteristics of players across markets. For example, Augureau et al. (2006) allow for the demographics of an Internet Service 
Provider's (ISP) service area to affect its preferred modem technology. Service areas overlap creating variation in the expected choices of an ISP's competitors and this allows strategic incentives to be identified. One might hope that exclusion restrictions could be found here as well. For example, if timing preferences were to vary systematically across owners (some firms like Clear Channel own stations in many markets) or across different music formats, then one might be able to identify strategic incentives using plausibly exogenous variation in the ownership or format mix across markets.

Unfortunately I show that observable station characteristics have very little affect on timing choices, especially during drivetime, so that even if the exclusion restrictions are valid, they will not be very useful in identifying strategic incentives. Instead I emphasize a more novel approach to identification which exploits the possible existence of multiple equilibria in the model and in the data. To see the intuition suppose that stations play a timing game with two alternative timing choices (1 and 2) which are equally attractive in terms of common factors (for example, neither is a quarter-hour). If stations want to coordinate then there may be an equilibrium where stations cluster their commercials at time 1 and another equilibrium where they cluster their commercials at time 2 . If some markets are in each equilibrium then the type of pattern that we would see in the data could look like Figure 2 which shows when stations in two markets played commercials during one particular hour. The distributions in both markets have three peaks, just like the aggregate distribution, but they are at noticeably different times. If stations want to play commercials at different times then we would expect to observe excess dispersion within markets (market distributions less concentrated than the aggregate) rather than clustering. If there is no strategic incentive then, if common factors are the same across markets, then there is no reason why we should observe either excess clustering or dispersion relative to the aggregate distribution. Therefore, if we can observe stations clustering at different times in different markets and we can make some assumptions about how common factors vary across markets, then we may be able to infer that stations want to coordinate on timing.

The idea that multiple equilibria can aid identification is not entirely new: in particular, Brock and Durlauf (2001) make this argument in their analysis of non-linear peer effect models. The underlying structure of our models is very similar, but I develop my results in the context of estimating a game where the number of players is relatively small. In contrast, Brock and Durlauf consider settings with 
Figure 2: Timing of Commercials in Orlando, FL and Rochester, NY on October 30, 2001 5-6 pm

(a) Orlando, FL

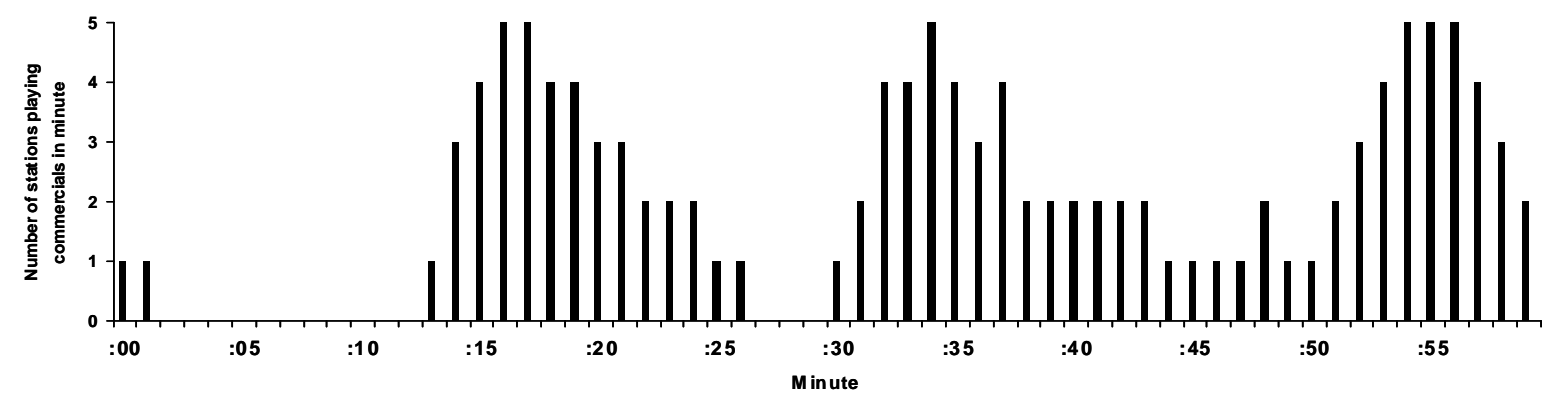

(b) Rochester, NY

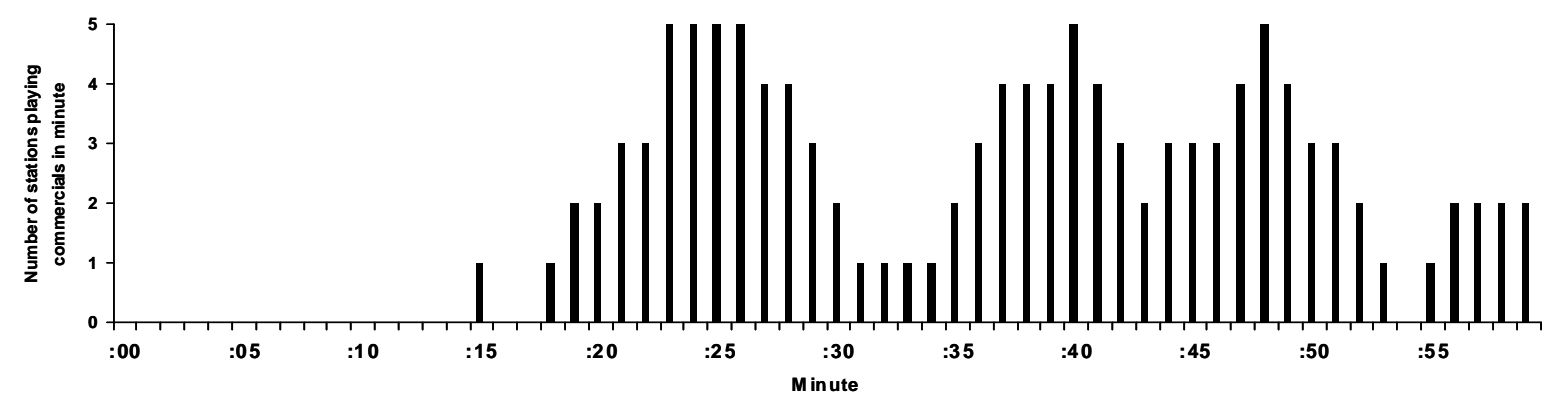

sufficiently many players that summary statistics on the actions of other players can simply be included as regressors in a single agent analysis. My approach - which raises some additional identification issues - is more naturally applicable in the type of settings usually considered by IO economists.

The obvious concern with relying on multiple equilibria for identification of strategic incentives is that some forms of heterogeneity in common factors across markets could generate patterns which look like multiple equilibria. I show that controlling for observable heterogeneity and allowing for parametric forms of unobserved heterogeneity does not change my results. Perhaps more convincingly I also show that there are differences in the results across markets and hours which are consistent with coordination. For example, strategic incentives should be stronger when listeners are more likely to switch stations (both $\theta$ parameters larger in the model). This is true during drivetime hours because in-car listeners, who are more numerous during drivetime, are closer to their dials/preset buttons. ${ }^{4}$

\footnotetext{
${ }^{4}$ MacFarland (1997), p. 89, reports that, based on a 1994 survey, $70 \%$ of in-car listeners switch at least once during a commercial break compared with $41 \%$ of at home and $29 \%$ of at work listeners. Arbitron estimates that $39.2 \%$ of listening is in-car during drivetime compared with $27.4 \% 10 \mathrm{am}-3 \mathrm{pm}$ and $25.0 \% 7$ pm-midnight (Fall 2001 data from the Listening Trends section of Arbitron's website, www.arbitron.com). Abernethy (1991) estimates that in-car listeners switch stations 29 times per hour on average.
} 
Consistent with this, and with stations wanting to coordinate, I find greater clustering and estimate a stronger incentive to coordinate during drivetime than outside drivetime. I also find that there is greater coordination in smaller markets, which typically have fewer stations, which is consistent with some models of listener behavior.

The paper is organized as follows. The rest of the introduction reviews the related literature. Section 2 describes the data. Section 3 presents the model of the timing game. Sections 4 and 5 discuss identification and estimation. Section 6 presents the empirical results and Section 7 concludes.

\section{$1.1 \quad$ Related Literature}

The observation that radio and TV stations tend to play commercials at the same time has motivated a small theoretical literature. Epstein (1998), Zhou (2000) and Kadlec (2001) assume that stations try to maximize the audience of commercials and show that in equilibrium stations play commercials at the same time. Sweeting (2006) provides theoretical models where strategic incentives should lead the degree to which commercials overlap in equilibrium to vary with the propensity of listeners to switch stations, which varies across hours, and market characteristics, such as the number of stations, ownership concentration and asymmetries in station listenership, together with some supporting reduced form evidence. I provide further evidence for these differences in the current paper, which comes out of the estimation of a more formal timing game.

I model stations as playing an incomplete information game. The incomplete information assumption has typically been used for convenience when there are many players, many actions or strategies are likely to be complicated (e.g., Seim (2006), Ellickson and Misra (2007), Augureau et al. (2006) and the recent literature on dynamic games). In my setting stations make timing choices simultaneously in real-time so incomplete information is more plausible. I present a simple test for imperfect information and find that I cannot reject this assumption. Bajari et al. (2007b, hereafter BHNK) provide formal identification results in incomplete information games, noting the current paper's contribution with respect to multiple equilibria. I use two common estimation procedures: a computationally light two-step approach (e.g., BHNK) and the Nested Fixed Point algorithm (NFXP, Rust (1987)). The two-step approach and the parameterization I use for the NFXP assume that a station uses the same 
strategy throughout my data and I present three tests which support this assumption.

Multiple equilibria have received more attention in games of complete information. I borrow from several papers in this literature (Bajari et al. (2007a), Bjorn and Vuong (1985), Ackerberg and Gowrisankaran (2006), Tamer (2003)) when specifying an equilibrium selection mechanism to close the model. Several recent papers, including Ciliberto and Tamer (2007) and Pakes et al. (2006), have shown that it is possible to estimate at least bounds on parameters in complete information games without specifying a selection mechanism. The emphasis in the current paper is different because I actually use the existence of multiple equilibria to identify strategic incentives.

\section{Data}

The data on the timing of commercials are extracted from airplay logs collected by Mediabase $24 / 7$, a company which uses electronic technologies to collect data on music airplay.

\subsection{Coverage of the Mediabase Sample}

I use logs from the first five weekdays of each month in 2001 for 1,091 music stations, including stations in the Adult Contemporary, Contemporary Hit Radio/Top 40, Country, Oldies, Rock and Urban formats as defined by BIAfn's MediaAccess Pro database. ${ }^{5}$ This database is also used to allocate stations to 144 markets, including all of the largest radio markets in the US with the exception of Puerto Rico. ${ }^{6}$ While some stations have listeners in multiple markets (e.g., Boston and Providence, RI), most of a station's listenership is in its market of license and I treat music stations licensed to a market as players in the timing game.

Unfortunately, the Mediabase sample does not cover include every licensed music station. Table 1 summarizes the coverage of the sample, splitting markets into two groups based on market size. In large markets, the sample includes over $70 \%$ of stations, and they account for over $86 \%$ of music station listenership because Mediabase concentrates on larger stations. The sample contains a smaller

\footnotetext{
${ }^{5}$ I combine stations in the Album Oriented Rock and Rock formats as stations in these formats play relatively similar music and seem to make similar timing choices. I drop observations for two station-quarters where BIAfn does not classify the station into one of these six formats.

${ }^{6}$ I drop observations from three markets (each with only one station) which enter the data only in December 2001. These stations were used in earlier versions of the paper without significant effects on the results.
} 
Table 1: Coverage of the Airplay Sample

\begin{tabular}{lcc}
\hline \hline & $\begin{array}{c}\text { Largest 70 Sample Markets } \\
\text { New York City, NY - } \\
\text { Knoxville, TN }\end{array}$ & $\begin{array}{c}\text { Smallest 74 Sample Markets } \\
\text { Albuquerque, NM - } \\
\text { Muskegon, MI }\end{array}$ \\
\hline $\begin{array}{l}\text { Average number of } \\
\text { music stations in market }\end{array}$ & 13.3 & 9.4 \\
$\begin{array}{l}\text { Average number of sample } \\
\text { stations in market }\end{array}$ & 10.3 & 4.9 \\
$\begin{array}{l}\text { Average \% of } \\
\text { music listening accounted } \\
\text { for by sample stations }\end{array}$ & 86.6 & 66.5 \\
\hline \hline
\end{tabular}

Note: statistics based on licensed commercial stations in the six formats listed above which had enough listeners to be rated by Arbitron throughout 2001

proportion of stations in smaller markets but it still includes two-thirds of music listenership. The panel is unbalanced over time, both because Mediabase sample expands during the year and some logs for individual station-days are missing. Overall there are 51,601 station-days of data, with up to 59 days per station. The issues which missing data create for estimating the model are discussed in Section 5 .

\subsection{Airplay Logs}

Table 2 shows an extract from an airplay log. The log lists the start time of each song and indicates whether there was a commercial break between songs. I estimate whether any particular minute has a commercial break using the following procedure:

1. the length of each song is estimated by the median time between songs with no commercials; ${ }^{7}$

2. a minute-by-minute schedule for each station-hour is created assuming that each song is played its full length unless this would erase a commercial break or overlap the start of the next song; and,

3. if the resulting breaks are more than five minutes long (a plausible maximum length), the break is shortened to five minutes by sequentially taking minutes from the end and then the start of the

\footnotetext{
${ }^{7}$ If a song is played less than 10 times without being followed by a commercial break, I asssume that the song is four minutes long, the median length of all songs.
} 
Table 2: Extract from a Sample Airplay Log

\begin{tabular}{llll}
\hline \hline Time & Artist & Title & Release Year \\
\hline 5:02 PM & LIFEHOUSE & Hanging By A Moment & 2000 \\
5:06 PM & 3 DOORS DOWN & Kryptonite & 2000 \\
5:08 PM & MORISSETTE, ALANIS & You Oughta Know & 1995 \\
5:12 PM & POLICE & Roxanne & 1979 \\
5:18 PM & PINK & Get the Party Started & 2001 \\
5:22 PM & BARENAKED LADIES & The Old Apartment & 1996 \\
5:24 PM & SUGAR RAY & Little Saint Nick & 1997 \\
5:26 PM & KEYS, ALICIA & Fallin' & 2001 \\
5:30 PM & KRAVITZ, LENNY & Dig In & 2001 \\
Stop Set & BREAK & Commercials and/or Recorded Promotions & - \\
5:40 PM & SHAGGY & Angel & 2000 \\
5:44 PM & TRAIN & Something More & 2001 \\
Stop Set & BREAK & Commercials and/or Recorded Promotions & - \\
5:54 PM & GOO GOO DOLLS & Black Balloon & 1999 \\
5:58 PM & CREED & With Arms Wide Open & 2000 \\
\hline \hline
\end{tabular}

break. This procedure increases the possibility of measurement error, so I drop station-hours with fewer than 8 songs as measurement errors are more likely when more time is unaccounted for.

\subsection{Definition of Timing Choices}

In common with the existing literature I specify a discrete choice game to estimate stations' strategic incentives. To do this, I need to specify a small number of timing options which stations will choose between. As the end of the hour has the most commercials, I classify stations into three groups: stations which are playing commercials at 50 minutes past the hour, stations which are playing commercials at 55 minutes past the hour and stations which are playing them at neither of these times. As I will show in Section 5, I can make assumptions under which it is consistent to simplify the game in this way. A complication arises if a station has commercials at both :50 and :55 (possible if the station has a short song between two breaks) but as I will show in a moment only a few station-hours have this feature and, for simplicity, I simply exclude them from the rest of the analysis.

While I have data from every hour of the day I focus the analysis on four hours. 4-5 pm and 5-6 pm are two hours in the middle of the afternoon drivetime period when many listeners will be in their cars and any strategic incentives should be quite strong. I focus on the afternoon drive because 
Table 3: Summary Statistics on Station Timing Choices

\begin{tabular}{|c|c|c|c|c|c|}
\hline \multirow[b]{2}{*}{ Hour } & \multicolumn{5}{|c|}{ Number of station-hours with } \\
\hline & total & $\begin{array}{c}\text { no commercial } \\
\text { at }: 50 \text { or }: 55\end{array}$ & $\begin{array}{c}\text { commercial airing } \\
\text { at }: 50, \text { not }: 55\end{array}$ & $\begin{array}{c}\text { commercial airing } \\
\text { at }: 55, \text { not :50 }\end{array}$ & $\begin{array}{l}\text { commercial airing } \\
\text { at both :50 and :55 }\end{array}$ \\
\hline $12-1 \mathrm{pm}$ & 50,567 & 23,611 & 13,858 & 12,896 & 202 \\
\hline $4-5 \mathrm{pm}$ & 50,520 & 22,118 & 13,878 & 14,231 & 293 \\
\hline $5-6 \mathrm{pm}$ & 50,361 & 22,300 & 13,886 & 13,917 & 258 \\
\hline $9-10 \mathrm{pm}$ & 49,828 & 23,756 & 12,812 & 13,079 & 184 \\
\hline
\end{tabular}

Table 4: Timing Choices by Format for $12-1 \mathrm{pm}$ and 5-6 pm

\begin{tabular}{|c|c|c|c|c|c|c|}
\hline \multirow[b]{2}{*}{$12-1 \mathrm{pm}$} & \multicolumn{6}{|c|}{ Format } \\
\hline & $\begin{array}{c}\text { Adult } \\
\text { Contemporary }\end{array}$ & CHR/Top 40 & Country & Oldies & Rock & Urban \\
\hline No commercial at $12: 50$ or $12: 55$ & 5,342 & 4,215 & 3,945 & 584 & 6,880 & 2,645 \\
\hline Commercial airing at 12:50 & 2,838 & 2,768 & 2,071 & 267 & 4,312 & 1,602 \\
\hline Commercial airing at 12:55 & 3,334 & 2,011 & 2,447 & 341 & 3,330 & 1,433 \\
\hline \multicolumn{7}{|l|}{$4-5 \mathrm{pm}$} \\
\hline No commercial at $4: 50$ or $4: 55$ & 5,158 & 3,994 & 3,724 & 523 & 6,361 & 2,540 \\
\hline Commercial airing at 4:50 & 3,155 & 2,488 & 2,439 & 334 & 3,876 & 1,594 \\
\hline Commercial airing at 4:55 & 3,191 & 2,516 & 2,376 & 330 & 3,928 & 1,576 \\
\hline
\end{tabular}

in the morning many stations have primarily talk programming and, because this leaves a lot of time which is unaccounted for in the log, it is difficult for me to locate commercials precisely: between 7 and 9 am more than $50 \%$ of station-hours fail to meet the 8 song criterion whereas less than $3 \%$ of station-hours do so in the afternoon. I use 12-1 am and 9-10 pm as two representative non-drivetime hours, although results look similar for several others which I have tried.

Table 3 shows the number of station-hours with commercials in each of the three slots, and the number which have commercials at both :50 and :55. This latter number is always small, so that dropping these station-hours should not introduce major biases. In every hour, between 50 and $60 \%$ of the remaining stations are playing commercials at either :50 or :55. Table 4 shows that timing choices vary relatively little across formats for $12-1 \mathrm{pm}$ and (especially) $4-5 \mathrm{pm}$. This is significant because a standard way to identify strategic incentives would be to use variation in timing preferences across formats and plausibly exogenous variation in the format mix of stations across markets. 


\subsection{Observable Station and Market Characteristics}

I allow for several observable variables to affect stations' preferences and the strength of strategic incentives. The first set of variables is a set of format dummies. The Rock format has the most stations (323). I define two dummies for stations owned by the largest radio companies, Clear Channel and Infinity (formerly CBS Radio). 310 (118) stations are owned by Clear Channel (Infinity) at some point during the year. Two variables describing market commuting patterns are calculated based on data from the 2001 US Census: the average commute time (average 26 minutes) and the average time at which people leave home for work in the morning $(7: 24 \mathrm{am})$. Unfortunately evening commute data are not available. Market rank is an ordinal measure of market size based on 2001 population $(1=$ New York City, 144=Muskegon, MI). A station's share is its share of music station listenership (averaged over the Spring and Fall quarters in 2001). The average share is 0.10. Ownership HHI is based on the ownership of music stations in the market, where each station is weighted equally (not by listenership). The median ownership HHI 0.29. A listenership asymmetry variable reflects the distribution of listenership across stations and it equals the sum of squared listenership shares divided by the number of stations, so it is minimized at 1 when all shares are equal. The median value of this variable is 1.23. The share, ownership HHI and listenership asymmetry variables are calculated using all music stations in the market which have enough listeners to be rated by Arbitron whether or not they are monitored by Mediabase. The HHI and asymmetry variables tend to be larger in smaller markets (the correlations with market rank are 0.38 and 0.35 respectively).

\section{An Incomplete Information Timing Game}

This section develops the incomplete information game used to model stations' timing decisions.

\subsection{Payoff Function}

There are $N_{m}\left(i=1, \ldots, N_{m}\right)$ stations in market $m(m=1, \ldots, M)$ and each of them chooses one of $T$ possible timing choices $(t=1, \ldots, T)$. As every market has more than one music station I assume that $N_{m} \geq 2$ even though there are some markets where only one station is observed. Station $i$ 's payoff 
from choosing action $t$ is

$$
\pi_{i m t}=X_{i m} \beta_{t}+\alpha P_{-i m t}+\varepsilon_{i m t}
$$

where $P_{-i m t}$ is the proportion of other stations in the market choosing action $t$. This payoff function is a "reduced form" in the sense that neither listener or advertiser behavior are modelled. A notable assumption, given that I have panel data, is that the model is static rather than dynamic. Section 6 shows that I cannot reject that each station uses the same choice probabilities throughout the one-year period of my data which is consistent with this static assumption (meaningful dynamics would cause stations to change their choice probabilities in response to the actions of other stations). ${ }^{8}$

The first term $\left(X_{i m} \beta_{t}\right)$ allows timing choices to have different average payoffs (e.g., lower for quarterhours) and for station characteristics to affect timing preferences. I make the standard normalization that $\beta_{1}=0$. Stations are identical when they do not differ in payoff-relevant characteristics.

The second term $\left(\alpha P_{-i m t}\right)$ determines the strategic interactions which are the focus of this paper. If stations want to coordinate then $\alpha>0$ whereas if they want to differentiate then $\alpha<0$. I assume that there are no strategic interactions across markets. The formulation embodies several assumptions, such as $\alpha$ being the same across markets, which I will relax in Section 6 .

The final term $\left(\varepsilon_{i m t}\right)$ is a random shock to a station's payoff from making a particular timing choice. I assume that $\varepsilon_{i m t}$ is private information to station $i$ so that the game is one of incomplete information. The interpretation of the $\varepsilon \mathrm{s}$ in my setting is that on any particular day a station has to fit commercial breaks around other pieces of programming (songs, competitions, weather updates) in real time and, because it would annoy listeners to cut these types of programming off, this creates some uncertainty about when commercials will be played. ${ }^{9}$ As this uncertainty is resolved in real time in ways which should be hard for other stations to predict, the private information assumption is reasonable. In Section 6 I will provide some evidence in favor of private information once I allow for

\footnotetext{
${ }^{8}$ One interpretation would be that any significant dynamics took place in years prior to my data and that there are no significant shocks during my data which would reintroduce dynamic forces.

${ }^{9}$ Modern scheduling software potentially gives program directors greater control over when commercials are played. However during drivetime stations typically use their most experienced DJs who are given a fair amount of discretion in creating programming which appeals to the listener. It is notable that TV commercials placed precisely in pre-recorded programming tend to overlap more than radio commercials. Warren (2001), p. 24 describes how playing commercials at a particular time "can be done some of the time. But it can't be done consistently by very many stations. Few songs are 2:30 minutes long any more". Gross (1988) says that the logistics involved in creating perfect "roadblocks" would be "nightmare".
} 
a persistent component of non-strategic preferences which is observed by all stations but not by the researcher.

\subsection{Station Strategies and Bayesian Nash Equilibria}

A station will choose the action which maximizes its expected payoffs given the strategies of other stations, i.e., $t$ will be chosen if and only if

$$
\begin{gathered}
\Pi_{i m t}\left(X_{i m t}, \sigma_{-i m t},\left(\alpha, \beta_{t}\right)\right)-\Pi_{i m t^{\prime}}\left(X_{i m t^{\prime}}, \sigma_{-i m t^{\prime}},\left(\alpha, \beta_{t}\right)\right) \geq \varepsilon_{i m t^{\prime}}-\varepsilon_{i m t} \forall t^{\prime} \neq t \\
\text { where } \Pi_{i m t}\left(X_{i m t}, \sigma_{-i m t},\left(\alpha, \beta_{t}\right)\right)=X_{i m t} \beta_{t}+\alpha \frac{\sum_{j \neq i} \sigma_{j m t}}{N_{m}-1}
\end{gathered}
$$

and $\sigma_{j m t}$ is the probability that station $j$ chooses action $t$ before the $\varepsilon$ s are realized and from the perspective of other stations who do not observe the $\varepsilon_{j}$ s. These choice probabilities are the most convenient way to represent strategies. It is also useful to define $\Pi_{i m}(\alpha, \beta)$ as the vector of differences between $\Pi_{i m t}$ and $\Pi_{i m 1}$ for actions $t=2, . ., T$

$$
\Pi_{i m}\left(X_{i m}, \sigma_{-i m} \alpha, \beta\right)=\left(\begin{array}{c}
\Pi_{i m 2}\left(X_{i m 2}, \sigma_{-i m 2},\left(\alpha, \beta_{2}\right)\right)-\Pi_{i m 1}\left(\sigma_{-i m 1}, \alpha\right) \\
\ldots \\
\Pi_{i m T}\left(X_{i m T}, \sigma_{-i m T},\left(\alpha, \beta_{T}\right)\right)-\Pi_{i m 1}\left(\sigma_{-i m 1}, \alpha\right)
\end{array}\right)
$$

The best response function $\sigma_{i m}=\Gamma\left(\Pi_{i m}\left(X_{i m}, \sigma_{-i m} \alpha, \beta\right)\right)$ maps from $\Pi_{i m}\left(X_{i m}, \sigma_{-i m} \alpha, \beta\right)$ into $i$ 's choice probabilities. The exact form of $\Gamma$ depends on the distribution assumed for the $\varepsilon$ s. In a Bayesian Nash equilibrium every station's strategy is a best response, so that $\sigma_{i m}^{*}=\Gamma\left(\Pi_{i m}\left(X_{i m}, \sigma_{-i m}^{*}, \beta\right)\right) \forall i$. A Bayesian Nash equilibrium is symmetric if all stations with the same characteristics have the same strategies. If $\alpha \geq 0$ then all equilibria must be symmetric. ${ }^{10}$ If $\alpha<0$ then there may be asymmetric strategies but it is easy to show that, for given parameters, strategies tend towards being symmetric as the number of stations increases. ${ }^{11}$

\footnotetext{
${ }^{10}$ Dropping market subscripts suppose that $i$ and $j$ are identical but that there are actions 1 and 2 for which $\sigma_{i 2}^{*}>\sigma_{j 2}^{*}$ and $\sigma_{j 1}^{*}>\sigma_{i 1}^{*}$. This implies that $\sum_{k \neq i} \sigma_{-k 1}>\sum_{k \neq j} \sigma_{-k 1}$ and that $\sum_{k \neq j} \sigma_{-k 2}>\sum_{k \neq i} \sigma_{-k 2}$ so that $\Pi_{j 2}>\Pi_{i 2}$ and $\Pi_{i 1}>\Pi_{j 1}$. These inequalities, the fact that $X_{i} \beta_{1}=X_{j} \beta_{1}$ and $X_{i} \beta_{2}=X_{j} \beta_{2}$ for identical players and the property that choice probabilities must be increasing in $\Pi_{i t}$ implies that $\sigma_{i 2}^{*}<\sigma_{j 2}^{*}$ and $\sigma_{j 1}^{*}<\sigma_{i 1}^{*}$, a contradiction.

${ }^{11}$ The intuition is simple: as $N_{m}$ increases $\frac{\sum_{j \neq i} \sigma_{-i m t}}{N_{m}-1}$ will look increasingly similar from the perspective of any two stations who will therefore have increasingly similar best response strategies.
} 
Brouwer's fixed point theorem guarantees the existence of at least one equilibrium but the number of equilibria can vary with the parameters. As an illustration suppose that there are two stations $(i$ and $j$ ), two actions ( 1 and 2 ), that $\varepsilon$ s are distributed extreme value (logit) and that $X_{j 2} \beta_{2}=0$. Figure 3 shows their reaction functions for four different cases, where $i(j)$ 's best response is on the vertical (horizontal) axis. In all cases $X_{i 2} \beta_{2}=0.1$ so $i$ has a preference for choosing action 2. In panel (a) and (b) $\alpha>0$ so stations want to choose the same times for commercials and the reaction functions slope upwards. In (a) the coordination incentive is relatively small and there is a single equilibrium. It is larger in (b), so that the $\mathrm{S}$ shape of the reaction function (which comes from the shape of the logit distribution) is more pronounced and there are 3 equilibria. The middle equilibrium (where $\left.\sigma_{i 2}^{*}=0.441, \sigma_{j 2}^{*}=0.439\right)$ is unstable in the sense that the application of iterated best responses close to this equilibrium would lead away from this equilibrium. The other equilibria involve the stations choosing the same action with greater probability and the action which they are most likely to choose differs across the equilibria. If $i$ 's preference for action 2 was increased then its reaction function would shift upwards and only the equilibrium involving coordination on action 2 would survive. This is consistent with the common intuition (e.g., Augureau et al. (2006)) that multiple equilibria are unlikely when stations differ substantially in payoff-relevant characteristics. I show that observable characteristics have little impact on timing choices especially during drivetime hours. In panels (c) and (d) $\alpha<0$ so stations want to choose different times for commercials. Once again when the strategic incentives are strong there are three equilibria, but this time they involve stations tending to choose different actions. A general property of the two action game when the $\varepsilon$ s have a bell-shaped distribution (e.g., logit or normal) is that there are at most three equilibria.

\subsection{Equilibrium Selection}

Estimation can require closing the model with an "equilibrium selection mechanism". This specifies that with $E$ possible equilibria, equilibrium $e$ is played with probability $\lambda_{e}, \sum_{e=1}^{E} \lambda_{e}=1$. 
Figure 3: Reaction Functions and Multiple Equilibria

(a) $\alpha=1$

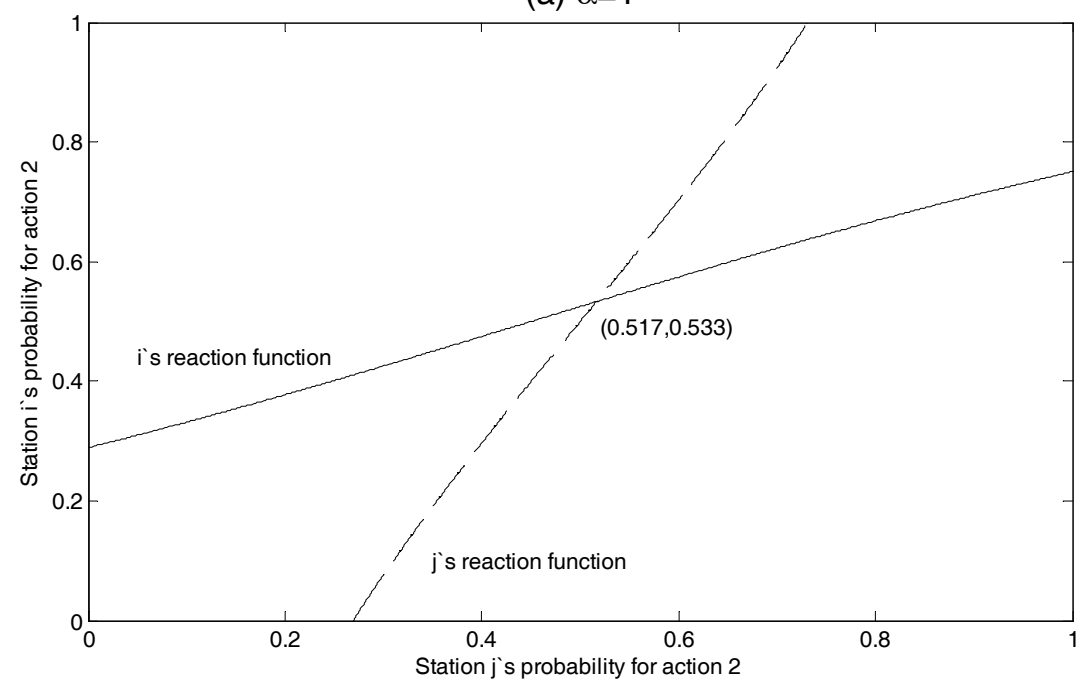

(c) $\alpha=-1$

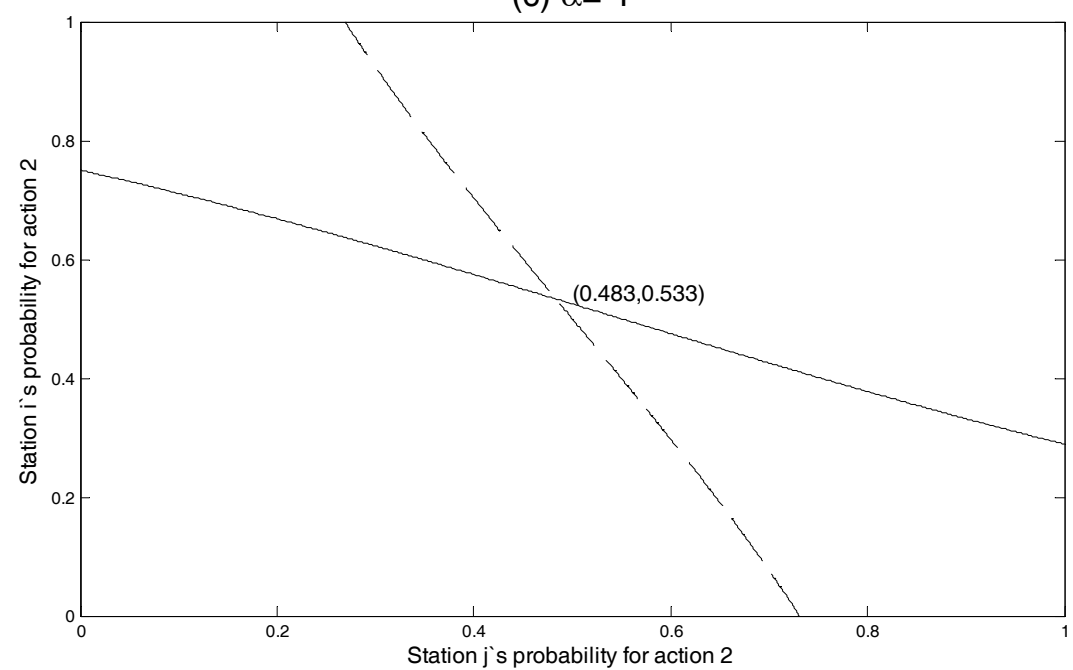

(b) $\alpha=2.4$

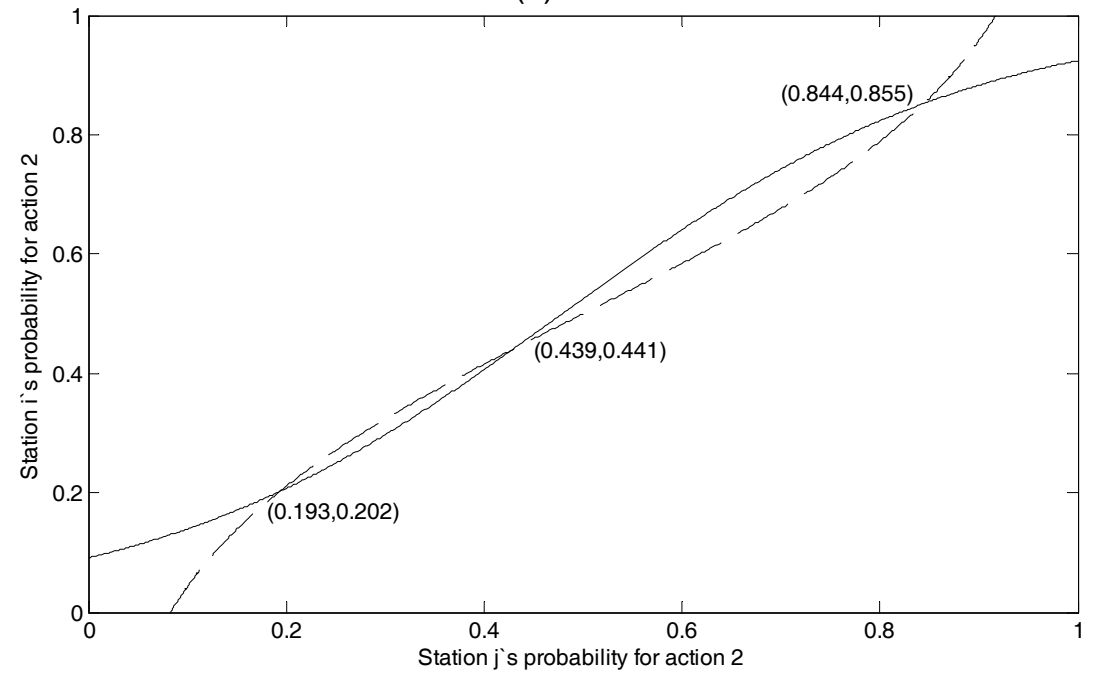

(d) $\alpha=-2.4$

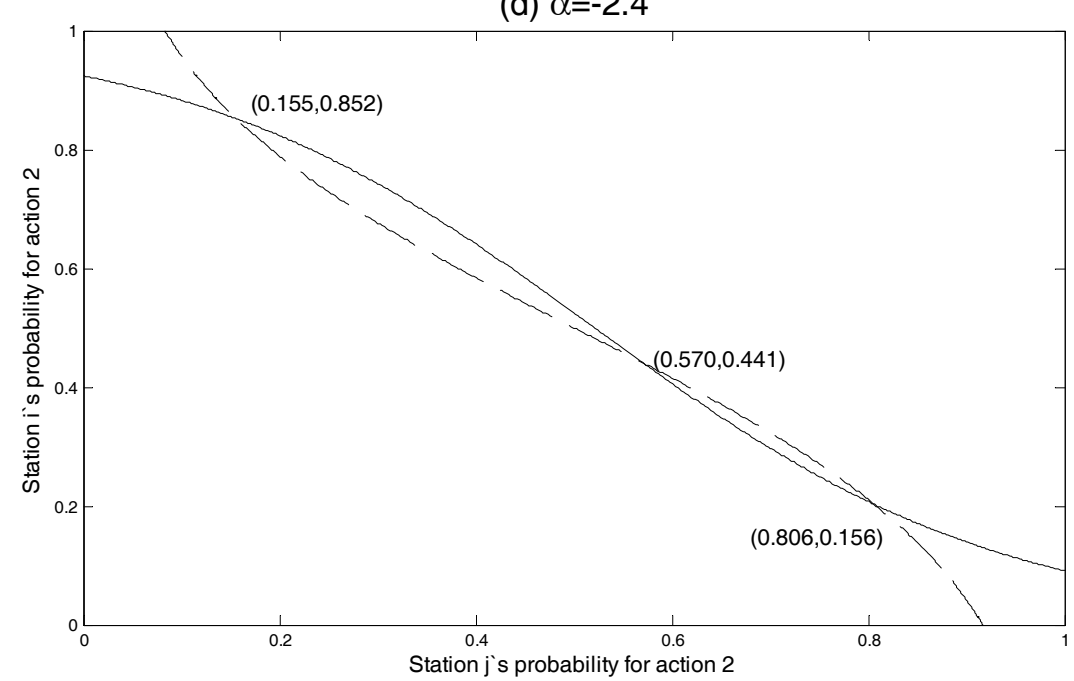




\section{Identification}

The data consists of observable characteristics and, as outcomes, the timing choice of each station. The parameters are identified if and only if a unique set of parameters gives rise to any set of probabilities for each outcome. I separate the discussion into two parts: first, the assumptions under which the payoff parameters are identified if the equilibrium choice probabilities of each station are known and second, the conditions under which equilibrium choice probabilities can be identified from the data.

\subsection{Identification of Payoff Parameters Given Equilibrium Choice Probabilities}

Previous studies of identification in discrete choice incomplete information games (BHNK, Pesendorfer and Schmidt-Dengler (2007)) have assumed that the researcher can observe equilibrium strategies for each station $\left(\sigma_{i m}^{*}\right)$. They have also assumed that a single equilibrium is played, and I will show why multiple equilibria can provide additional identification in this case. Throughout I assume that $\beta_{1}=0$ and that the $\varepsilon$ s are iid with a known parametric distribution. BHNK, p. 9 argue that these assumptions are necessary for identification. Hotz and Miller (1993) show that $\Gamma$ function, which maps differences in choice specific value functions to choice probabilities, can be inverted so that for each distinct set of equilibrium choice probabilities there are $T-1$ linearly independent equations of the form

$$
\Gamma^{-1}\left(\sigma_{i m}^{*}\right)=X_{i m t} \beta_{t}+\alpha\left(\frac{\sum_{j \neq i} \sigma_{j m t}-\sum_{j \neq i} \sigma_{j m 1}}{N_{m}-1}\right) \text { for } t=2, . ., T
$$

\subsubsection{Identical Stations}

The helpful role of multiple equilibria can be seen most clearly when stations are identical ( $X_{i m}$ is the same for all stations in all markets). In this case there are $T$ payoff parameters $\left(\beta_{2}, \ldots, \beta_{T}, \alpha\right)$. The first identification result is negative.

Proposition 1. If stations are identical and a single symmetric equilibrium is played in every market then the parameters are not identified.

Proof. If stations in all markets are identical and a single symmetric equilibrium is played then $\sigma_{i m t}^{*}=$

$\sigma_{-i m t}^{*}=\sigma_{j n t}^{*} \forall i, j, m, n, t$ so that the strategies of each station yield an identical set of linear equations. ${ }^{12}$

\footnotetext{
${ }^{12}$ The proportional formulation of the strategic incentive in the payoff function implies that symmetric equilibrium
} 
There are $T$ parameters and $T-1$ linear equations so the parameters are not identified.

The choice probabilities also place no restrictions or bounds on the parameters in this case, i.e., for any $\alpha$ we can find $\beta$ s which generate any observed set of equilibrium choice probabilities. ${ }^{13}$

Proposition 2. If stations are identical and at least two equilibria are played then the parameters are identified.

Proof. One equilibrium provides $T-1$ linear equations. A second equilibrium must have at least two equilibrium choice probabilities which are different from the first, providing at least one additional linearly independent equation. Hence, the $T$ parameters are identified.

Additional equilibria would provide additional equations, so that the parameters will be overidentified. The logic of the proof also shows that the parameters will be identified with asymmetric equilibria, as there will be additional equations for each set of equilibrium choice probabilities.

\subsubsection{Non-Identical Stations}

If stations differ in observable characteristics which affect timing preferences then additional variation can identify the parameters. In particular, suppose that exclusion restrictions can be made so that a station's own characteristics only directly affect its own timing preferences. In this case, variation in the characteristics of other stations in a market will create additional sets of equations like (4) as the $\sum_{j \neq i} \sigma_{j m t} \mathrm{~S}$ will vary for given values of $X_{i m t} .{ }^{14}$ BHNK show that the parameters are nonparametrically identified when there is sufficient variation in the characteristics of other stations. Of course, multiple equilibria will still provide additional equations, and they may be particularly valuable when variation in station characteristics is limited (e.g., there are a few discrete types). The helpful role of multiple equilibria in this context is discussed by Brock and Durlauf (2001).

strategies will form equilibria in markets with any $N_{m} \geq 2$.

${ }^{13}$ Of course, if one observed markets with one station (so only non-strategic preferences would affect choices) then one could identify strategic incentives from the differences in strategies between monopoly and oligopolistic markets. However, there are no monopoly markets in my data.

${ }^{14}$ Note that having non-identical stations is not enough: variation in the set of station characteristics across markets is also required. To see this suppose that there are three types of station and one station of each type in every market. If the same equilibrium is played in every market then there are $3(T-1)+1$ parameters and $3(T-1)$ equations so the parameters are not identified. 


\subsection{Identification of Equilibrium Choice Probabilities From Observed Outcomes}

When a single symmetric equilibrium is played the identification of equilibrium choice probabilities is trivial because, with infinite data, they can be estimated by the frequency with which each action is chosen conditional on station characteristics. This argument fails with multiple or asymmetric equilibria. However, the equilibrium choice probabilities are still identified under certain conditions.

\subsubsection{Panel Data and Equilibrium Assumptions}

Suppose that we observe a long panel of data on station choices. If we assume that each station uses one strategy over time then we can identify each station's equilibrium choice probabilities from its own choice frequencies. This approach allows for asymmetric equilibria because the strategy of each station can be identified without assuming that stations which appear identical use the same strategy. The assumption that one equilibrium is played within each market over time has been made previously by Pesendorfer and Schmidt-Dengler (2007) and Ellickson and Misra (2007). I will show below that this assumption is consistent with the data.

\subsubsection{Symmetric Equilibria and Identified Equilibrium Selection Mechanisms}

With only cross-sectional data or a short panel it is necessary to identify the mixture of equilibrium choice probabilities in the data. The equilibrium selection mechanism defines the frequency with which each equilibrium occurs in the data.

The requirements for identification are easily seen when there are two actions $(t=1,2)$, stations are identical and equilibria are symmetric. Dropping market subscripts (markets are identical), suppose that there are $N$ stations and up to $E$ equilibria and that in equilibrium $e$ action 2 is chosen with probability $\sigma_{e 2}^{*}$ and this equilibrium is played with probability $\lambda_{e}$. The probability that $n_{2}$ stations choose action 2, which can be observed in the data, is

$$
\operatorname{Pr}\left(N_{2}=n_{2}\right)=\sum_{e=1}^{E} \lambda_{e}\left(\begin{array}{c}
N \\
n_{2}
\end{array}\right)\left(\sigma_{e 2}^{*}\right)^{n_{2}}\left(1-\sigma_{e 2}^{*}\right)^{N-n_{2}} \quad \sum \lambda_{e}=1
$$

which is the pmf of a binomial mixture model with $E$ possible components. This model has $2 E-1$ 
parameters $\left(E \sigma_{e 2}^{*} \mathrm{~s}\right.$ and $\left.E-1 \lambda_{e} \mathrm{~s}\right)$ and there are $N$ linearly independent equations (5). Teicher (1963) shows that the parameters are identified if and only if there are $N \geq 2 E-1$ stations (when $N$ varies across markets we need some markets with at least $2 E-1$ stations). The same condition holds with more actions (Kim (1984) and Elmore and Wang (2003)) which is intuitive because a multinomial model can always be broken down into a set of binomial models with stations choosing an action or its complement.

The intuition for identification of a mixture is that a mixture generates excess variance in the number of stations choosing a particular outcome. Figure 4(a) shows a theoretical example. The black bars show the pmf for the number of stations choosing action 2 when there are two choices, $N=8$, and there is a single symmetric equilibrium with identical stations and each station chooses action 2 with probability 0.5 . The white bars show the pmf when there is an equal mixture of two symmetric equilibria. In the first equilibrium each station chooses action 2 with probability 0.6 and in the second equilibrium each station chooses action 2 with probability 0.4 . The probabilities of outcomes with many stations choosing action 1 and outcomes with many stations choosing action 2 are both higher when there are multiple equilibria. Note that if stations want to choose different times for commercials and an asymmetric equilibrium is played then outcomes with many stations choosing the same action will have lower probability than could be generated by a single symmetric equilibrium. In this case, there will be too little variance in the number of stations choosing a particular action, not too much.

The remaining panels of Figure 4 show similar pictures constructed using data from 12-1 pm and 5-6 pm (as sample drivetime and non-drivetime hours). The red lines show the distribution of the observed proportion of stations in a market-day-hour which play commercials at :55 out of the set of stations playing commercials at either :50 or :55. I condition in this way in order to make the figure comparable to (a), but stations making neither of these choices will not be ignored below. Panel (b) shows the distribution for all markets, and panel (c) shows the distribution for the smallest 74 markets (roughly breaking the dataset in half based on market size). For both size groups the density for $12-1 \mathrm{pm}$ is more concentrated around 0.5 than the density for 5-6 pm, consistent with there being more clustering of commercials during drivetime. The solid black lines show the expected density if a single symmetric 
Figure 4: Identification: Theory and Evidence

(a) Comparison of PDF for Number of Stations Choosing :55 for a Model with One or Two Equilibria

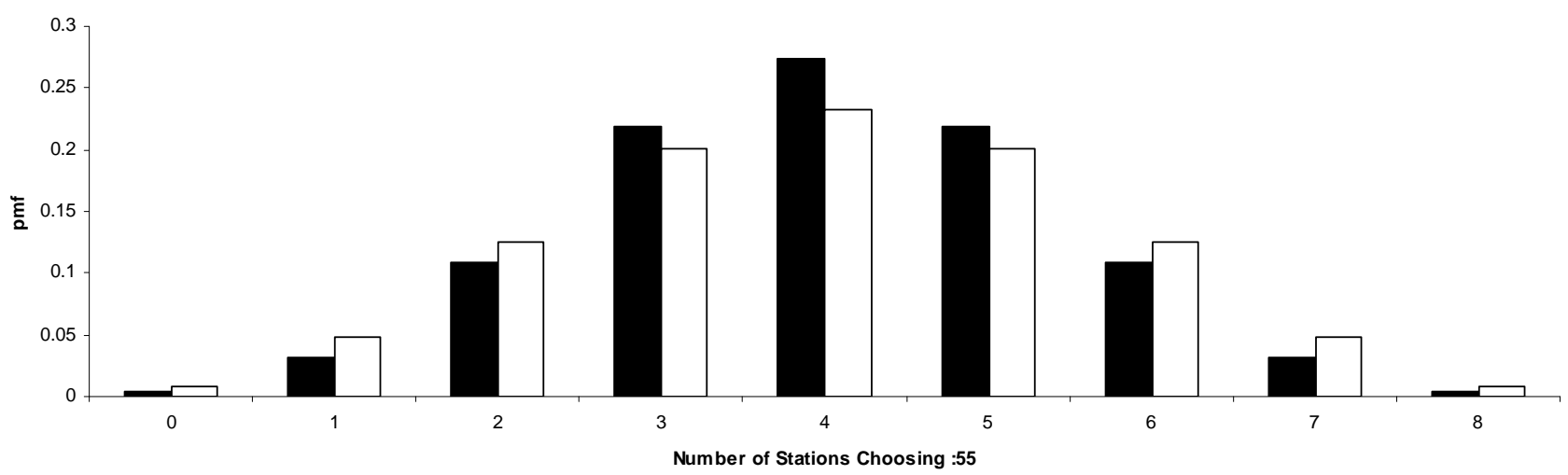

Single Equilibrium, :55 Chosen with probability 0.5 口Equal Mixture of Two Symmetric Equilibria, :55 Chosen with probabilities 0.6 and 0.4

(b) Proportion of Stations Playing Commercials at :55 Conditional on Playing them at:50 or :55, All Markets Red Line $=$ Kernel Density for Actual Data, Black Lines $=$ Expected Kernel Density for a Binomial Model $+/-1$ Std Error
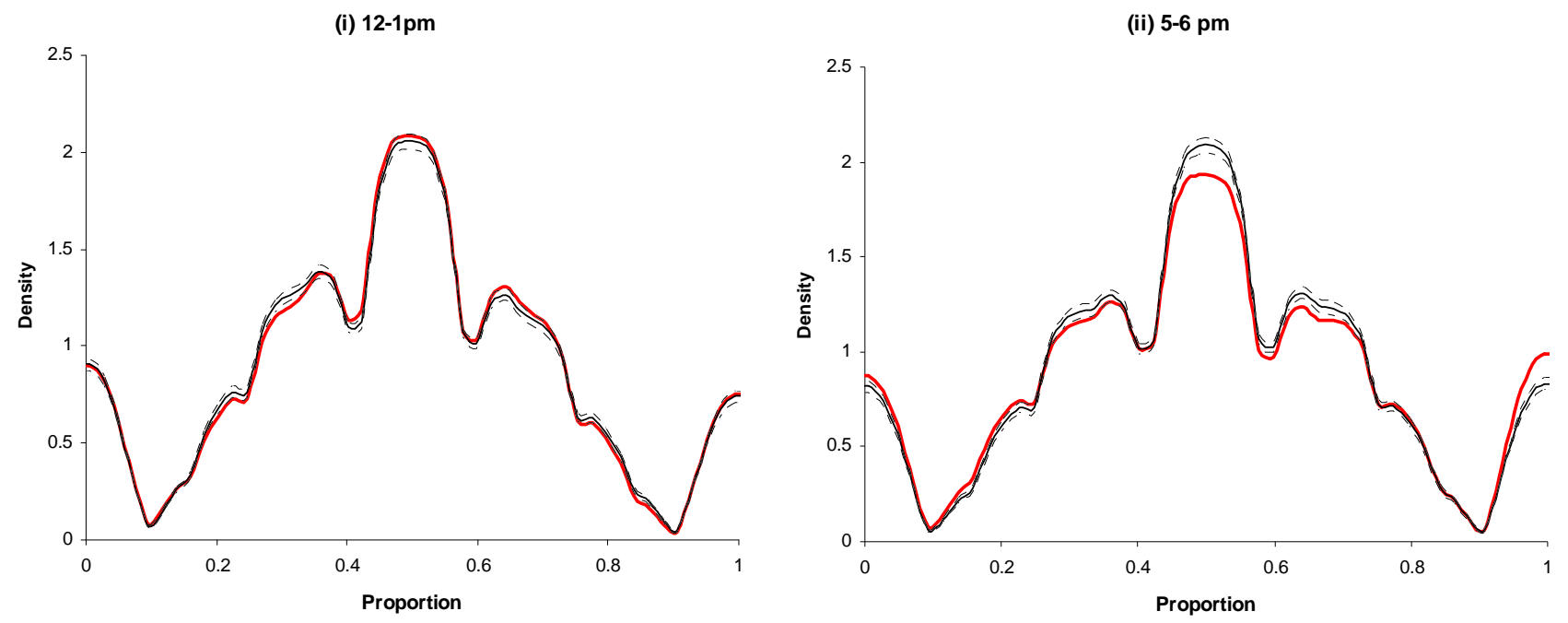

(c) Proportion of Stations Playing Commercials at :55 Conditional on Playing them at:50 or :55 in 74 Smallest Markets (Albuquerque, NM and smaller)

(i) $12-1 \mathrm{pm}$

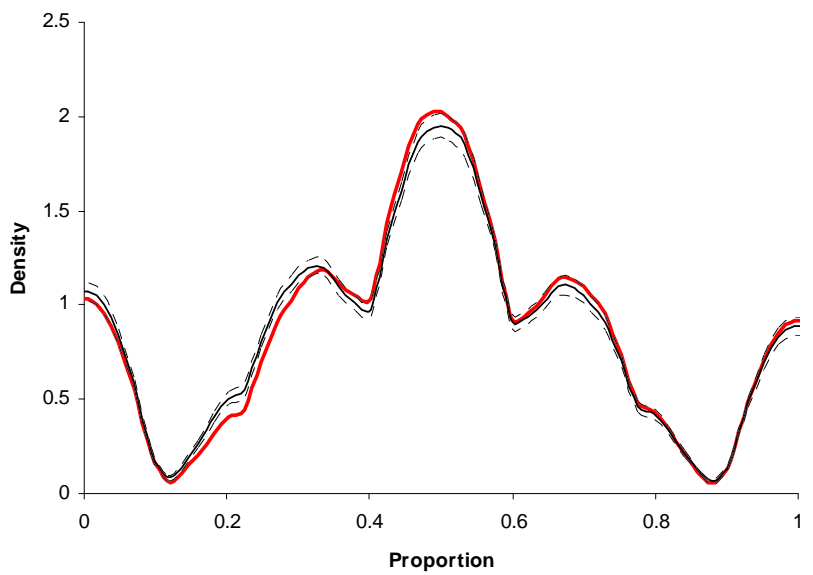

(ii) 5-6 pm

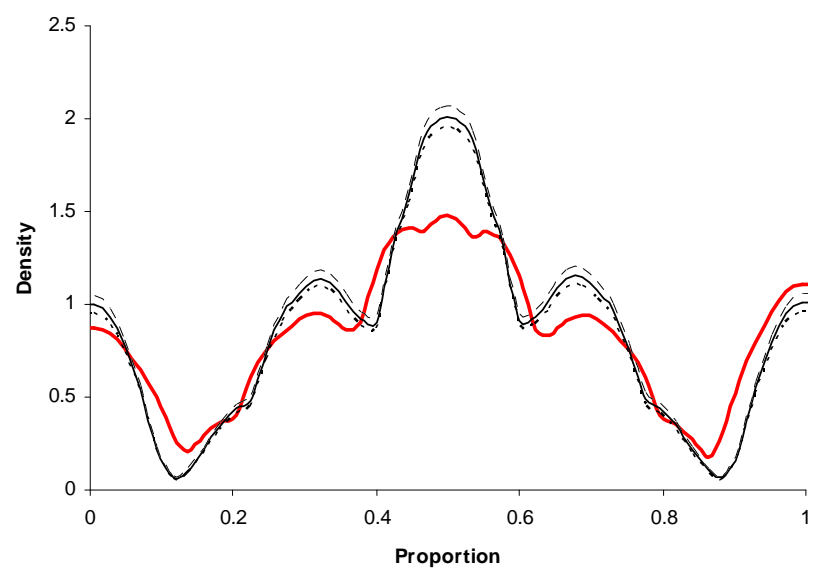


equilibrium was played with each station choosing :55 with the probability that I observe it being chosen in the actual data. Even though this simple model ignores any observable differences across stations or markets which may affect timing choices, it fits the 12-1 pm data almost perfectly, with the actual density being significantly different from the expected density (i.e., outside the $+/-1$ standard error dashed lines) at only a few points. On the other hand, for 5-6 pm the distribution has greater variance than the single symmetric equilibrium model predicts. The differences are particularly large in smaller markets, and this will be consistent with the results below where I find that incentives to coordinate are stronger and multiple equilibria are more common in smaller markets during drivetime. ${ }^{15}$

The statistical mixture model literature has not considered models which would correspond to ones in which stations in a market are not identical. However, the previous logic can be used to show that identification does not become more difficult in this case. Suppose that there are two actions and $S$ observable types of station with $N_{s}$ stations of type $s$ using symmetric equilibrium choice probabilities $\sigma_{e s}^{*}$. There are now $S * E+E-1$ parameters $\left(S * E \sigma_{e s}^{*} \mathrm{~s}\right.$ and $\left.E-1 \lambda_{e} \mathrm{~s}\right)$ and $\prod_{s=1}^{S}\left(N_{s}+1\right)-1$ observable probabilities

$$
\operatorname{Pr}\left(N_{21}=n_{21}, . ., N_{2 S}=n_{2 S}\right)=\sum_{e=1}^{E} \lambda_{e} \prod_{s=1}^{S}\left(\begin{array}{c}
N_{s} \\
n_{2 s}
\end{array}\right)\left(\sigma_{e s}^{*}\right)^{n_{1 s}}\left(1-\sigma_{e s}^{*}\right)^{N-n_{1 s}} \quad \sum \lambda_{e}=1
$$

Identification still depends on having enough stations relative to the number of equilibria but notice that the number of observed probabilities (equations) increases geometrically in the number of types while the number of parameters increases only linearly. This means that, for example, the equilibrium choice probabilities and the selection mechanism are identified when one has two equilibria and three stations each of a different type.

\footnotetext{
${ }^{15}$ Rysman and Greenstein (2005)'s Multinomial Test of Agglomeration and Dispersion (MTAD) provides an alternative way of testing whether there are more markets where very many or very few stations choose the same action. Applying the MTAD for the binomial choice model (:50 or :55 conditional on one of these actions being chosen) shows that there is significant clustering during both drivetime hours ( $\mathrm{p}$-values 0.000 ) but not outside drivetime ( $\mathrm{p}$-value 0.79 for 12 - $1 \mathrm{pm}$ and 0.44 for $9-10 \mathrm{pm})$. Examining the multinomial choice $(: 50,: 55$ or neither) one finds significant clustering in all four hours, although the test statistics are between 4 to 5 times larger for the drivetime hours.
} 


\section{Estimation}

This section explains my estimation strategy. I start by showing why I am able to estimate stations' strategic incentives using only a subset of choices, before outlining two different estimation procedures.

\subsection{Estimation Using A Subset of Choices}

It is computationally difficult to solve or estimate the game allowing for many possible timing choices, multiple equilibria and different kinds of unobserved heterogeneity. However, I can still estimate stations' strategic incentives using data on just two choices (playing ads at :50 or :55) if the $\varepsilon$ s are iid extreme value. To see why, label these timing choices 1 and $2\left(\beta_{1}=0\right)$. The probability that station $i$ chooses action 2 from the full set of $T$ possible actions is

$$
\sigma_{i m 2}^{*}=\frac{\exp \left(X_{i m} \beta_{2}+\alpha \frac{\sum_{j \neq i} \sigma_{j m 2}^{*}}{N_{m}-1}\right)}{\sum_{t=1}^{T} \exp \left(X_{i m} \beta_{t}+\alpha \frac{\sum_{j \neq i} \sigma_{j m t}^{*}}{N_{m}-1}\right)}
$$

and the probability of action 2 conditional on action 1 or action 2 being chosen $\left(\sigma_{i m(2 \mid 1 \text { or } 2)}^{*}\right)$ is

$$
\sigma_{i m(2 \mid 1 \text { or } 2)}^{*}=\frac{\exp \left(X_{i m} \beta_{2}+\alpha\left(\frac{\sum_{j \neq i}\left(2 \sigma_{j m(2 \mid 1 \text { or } 2)}^{*}-1\right) \sigma_{j m(1 \text { or } 2)}^{*}}{N-1}\right)\right)}{1+\exp \left(X_{i m} \beta_{2}+\alpha\left(\frac{\sum_{j \neq i}\left(2 \sigma_{j m(2 \mid 1 \text { or } 2)}^{*}-1\right) \sigma_{j m(1 \text { or } 2)}^{*}}{N-1}\right)\right)}
$$

where $\sigma_{j m(1 \text { or } 2)}^{*}$ is the probability that station $j$ chooses action 1 or action $2 . \quad \beta_{2}$ and $\alpha$ can be consistently estimated using the conditional choice probabilities in (8) as long as I adjust appropriately for the probabilities that one of these choices is made by other stations $\left(\sigma_{j m(1 \text { or } 2)}^{*}\right){ }^{16}$

Variation in the proportion of stations choosing one of the two actions, potentially due to multiple equilibria in the full game, can identify the parameters even if there is a single equilibrium in the conditional two action game. The intuition is straightforward. Suppose that stations want to play their commercials at the same time. If other stations are unlikely to play commercials at the end of the hour then the incentives of a station which is playing a commercial then to try to coordinate with

\footnotetext{
${ }^{16}$ Note that it does not simplify matters to consider players choosing between action 2 and not action 2 . In this case, the probability of choosing action 2 is given by (7) which depends on all of the parameters. One way of viewing the problem is that, without additional parameters, it is not clear whether stations get a benefit from coordinating when many of them choose "not action 2".
} 
other stations are weak because it will likely only overlap with a small proportion of stations. On the other hand, strategic incentives in the conditional game will be stronger when more stations are likely to play commercials then.

This type of correlation is observed in the data. I created a dataset with observations on pairs of stations in the same market, day and hour where both of the stations play commercials at either :50 or :55. I also calculated the average proportion of other stations in the market which play commercials at either of these times, and ran a linear probability model regressing a dummy variable for both of the stations playing commercials at the same time (both at :50 or both at :55) on the proportion variable for other stations. The correlation is positive in all hours, and it is significant at the $5 \%$ level for 4-5 pm. When the proportion variable is interacted with the rank of the market (higher for smaller markets), the interaction coefficients are positive and significant at the $0.1 \%$ level for both of the drivetime hours (insignificant outside drivetime). These correlations are consistent with the results below which show that stations want to coordinate on timing during drivetime and have stronger incentives in smaller markets.

\subsection{Two Step Estimation}

The two step estimation approach follows the panel data identification argument set out above. If a station uses the same strategy throughout my data then its equilibrium choice probabilities can be estimated by

$$
\widehat{\sigma_{j m t}}=\frac{\sum_{d=1}^{D_{j m}} I_{j d m t}}{D_{j m}}
$$

where $I_{j d m t}$ is equal to 1 if station $j$ chooses action $t$ on day $d$ and $D_{j m}$ is the number of days that station $j$ is observed in my data. These estimates can be used to calculate the terms in the inner brackets on the right-hand side of (8) and a binomial logit model can be used to estimate $\beta_{2}$ and $\alpha$. A necessary assumption is that whether an airplay log is missing is not related to a station's timing choice. Standard errors are calculated using a bootstrap where markets are resampled. 


\subsection{Nested Fixed Point Estimation (NFXP)}

The NFXP algorithm solves for the conditional equilibrium choice probabilities at each iteration of the parameters. The specification which I use assumes that each station uses one strategy throughout my data. The probabilities that stations choose actions 1 or 2 are parameterized in the following flexible way

$$
\sigma_{i m(1 \text { or } 2)}^{*}=\frac{\exp \left(\beta_{1 \text { or } 2}+\eta_{i}+\eta_{m}\right)}{1+\exp \left(\beta_{1 \text { or } 2}+\eta_{i}+\eta_{m}\right)} \eta_{i} \sim N\left(0, \gamma_{i}^{2}\right), \eta_{m} \sim N\left(0, \gamma_{m}^{2}\right)
$$

which allows for persistent station and market heterogeneity. A market may have persistently few commercials at :50 and :55 because stations coordinate on having commercials at a different time (e.g., :40). $\quad \beta_{1 \text { or } 2}, \gamma_{i}$ and $\gamma_{m}$ are parameters to be estimated together with $\beta_{2}$ and $\alpha .^{17} \eta_{i}$ and $\eta_{m}$ are assumed to be known to all stations when they choose their conditional choice probabilities $\sigma_{i m(1 \text { or } 2)}^{*}$.

The simplest NFXP model consists the equations (10) and (8), with no unobserved heterogeneity in the $\beta_{2}$ or $\alpha$ parameters. Estimation proceeds in the following steps:

1. $S$ (50 or 100 depending on the model) sets of Halton draws for $e_{i}$ and $e_{m}$ are drawn from a standard normal distribution for each station and market. Draws are made and the game is solved for all music stations whether or not they are in the Mediabase sample. ${ }^{18} e_{i}$ and $e_{m}$ are held constant during estimation while $\eta_{i}^{s}=\gamma_{i} e_{i}^{s}$ and $\eta_{m}^{s}=\gamma_{m} e_{m}^{s}$ vary with the parameters;

2. for each market for a given set of the parameters and draws,

(a) (10) is used to calculate $\sigma_{i m(1 \text { or } 2)}^{*}$;

(b) the equilibrium choice probabilities $\sigma_{i m(2 \mid 1 \text { or 2) }}^{*}$ are solved for by iterating best responses (8). Experimentation showed that to reliably find multiple equilibria, it is necessary to begin the iteration process from extreme points in the strategy space (e.g., every station chooses action 1 with probability 0.99 or 0.01 ) and to update strategies rather slowly. ${ }^{19}$ I take strategies to have converged when the choice probabilities change by less than $1 e-8$.

\footnotetext{
${ }^{17}$ Regressions (which are available on request) indicate that observable station and market characteristics have at most small effects on the probability that actions 1 and 2 are chosen and for computational reasons these variables are not included in the specification.

${ }^{18} \mathrm{I}$ include all commercial music stations with at least $1 \%$ shares of radio listening at some point during 2001.

${ }^{19}$ For example, in some models I update choice probabilities by the maximum of 0.001 or $2.5 \%$ of the difference between the current strategy and the best response. Updating more quickly can cause one of the equilibria to be missed.
} 
This approach can only find stable and symmetric equilibria and, for given values of the $\sigma_{i m(1 \text { or } 2)^{\mathrm{S}}}^{\mathrm{S}}$, the conditional game can have at most two stable and symmetric equilibria;

3. the choice probabilities are used to calculate the simulated log-likelihood based on the stationdays which are observed in the sample

$$
\begin{gathered}
\ln L=\sum_{m=1}^{M} \ln \frac{1}{S} \sum_{s=1}^{S} \\
\left(\begin{array}{c}
\lambda \prod_{i=1}^{N_{m}}\left[1-\sigma_{i m(1 \text { or } 2)}^{s}\right]^{n_{i m 0}}\left[\sigma_{i m(1 \text { or } 2)}^{s}\left(1-\sigma_{i m A(2 \mid 1 \text { or } 2)}^{s *}\right)\right]^{n_{i m 1}}\left[\sigma_{i m(1 \text { or } 2)}^{s} \sigma_{i m A(2 \mid 1 \text { or } 2)}^{s *}\right]^{n_{i m} 2} \\
+(1-\lambda) \prod_{i=1}^{N_{m}}\left[1-\sigma_{i m(1 \text { or } 2)}^{s}\right]^{n_{i m 0}}\left[\sigma_{i m(1 \text { or } 2)}^{s}\left(1-\sigma_{i m B(2 \mid 1 \text { or } 2)}^{s *}\right)\right]^{n_{i m 1}}\left[\sigma_{i m(1 \text { or } 2)}^{s} \sigma_{i m B(2 \mid 1 \text { or } 2)}^{s *}\right]^{n_{i m 2}}
\end{array}\right)
\end{gathered}
$$

where $n_{i m t}$ is the number of days on which station $i$ chooses action $t$ and action 0 is choosing neither action 1 nor action 2. $\sigma_{i m A(2 \mid 1 \text { or } 2)}^{s *}$ is the conditional equilibrium choice probability of choosing action 2 in equilibrium A given simulation draws $s$, observed station market characteristics and the structural parameters; and,

4. the parameters are updated using the Nelder-Mead algorithm and steps 2 and 3 are iterated until the parameters converge.

I also estimate models which allow for unobserved heterogeneity in the remaining parameters $\left(\beta_{2}\right.$ and $\alpha$ ). Estimation of these models requires drawing additional simulation draws in step 1 and the including them in the calculation of the equilibrium choice probabilities in step 2(b). I calculate standard errors analytically treating markets as observations.

An additional problem which arises is that the simulated log-likelihood can have multiple local maxima, a common problem in mixture models (McLachlan and Peel (2000)). In practice, I only found this problem to be significant when several forms of heterogeneity were included and different maxima only had significantly different coefficients for the listenership asymmetry and ownership HHI variables, for which the results are weak in any event. Below I present the log-likelihood-maximizing coefficients starting from several different starting points. 


\subsection{Comparison of the Two Estimation Procedures}

I present the results using two estimation procedures because they have different strengths and weaknesses when applied to the type of data that I have. The two-step procedure would generate consistent estimates if I had a sufficiently long panel of data without missing stations. In practice, there is limited data on any station-hour (maximum 59 observations) and some stations are missing entirely, so that my estimates of a station's expectations about what other stations will choose (the inner brackets on the right-hand side of (8)) are likely to be inaccurate. This is likely to bias the two-step estimates of strategic incentives downwards and the bias may be larger in smaller markets where the sample is less complete. However, the computational simplicity of the two-step procedure allows me to estimate several specifications and to control for lots of observable characteristics. With these results I can choose a plausible specification for the computationally-intensive NFXP procedure, which can generate consistent and efficient estimates as long as the fact that data is missing is not related to timing

choices. For this reason my discussion of the size of the strategic incentives will focus on the NFXP results.

\section{Empirical Results}

I present the empirical results in the following order. Section 6.1 presents three tests of the assumption that each station uses one strategy throughout my data. Sections 6.2 and 6.3 present the two-step and NFXP estimates respectively.

Specifications are estimated separately for each hour, and I expect any strategic incentives to be stronger during drivetime. I also allow strategic incentives to vary with three observable market characteristics: market rank (higher for smaller markets), ownership concentration and listenership asymmetry. The intuitions for why these variables may affect strategic incentives if stations want to coordinate are fairly simple (Sweeting (2006) describes theoretical models examining these comparative statics).

Smaller markets typically have fewer stations. If switching listeners try every station before listening to a commercial then a station will only be able to maintain its audience during a commercial 
if every station plays commercials at the same time. The probability that this happens increases when there are fewer stations, increasing the incentive of every station to try to coordinate. ${ }^{20}$ A similar result holds if listeners try only a sample of stations but they try more stations in larger markets. Asymmetries in station listenership can strengthen coordination incentives if switchers are much more likely to try one or two dominant stations. In this case, a station can keep most of its audience as long as it plays commercials at the same time as just one or two stations giving it more incentive to try to coordinate than in a market where stations are symmetric. Ownership concentration should lead to more coordination because there are externalities in the timing game: a station's timing decision will affect the audience of other stations as well as its own. Commonly owned stations should internalize these effects, and, because strategies are strategic complements if $\alpha>0$, common ownership should lead to other stations coordinating more as well. ${ }^{21}$ If stations want to differentiate then we would expect commercials to overlap less when ownership is more concentrated.

\subsection{Testing for Changes in Station Strategies/Within Market Multiple Equilibria}

The two-step procedure and the NFXP specification assume that each station uses the same strategy throughout my data. This implies that the same equilibrium is played within a market over time. I test this assumption using three tests which exploit different features of the data. One of tests (the pairwise correlation test) also provides evidence in favor of the incomplete information assumption.

\subsubsection{Modified Likelihood Ratio Test (MLRT)}

MLRTs have been developed in the statistics literature (Chen et al. (2001) and Chen et al. (2004)) to test for the appropriate number of components in binomial mixture models. Here I apply the Chen et al. (2001) test market-by-market to examine whether there is evidence of multiple equilibria being played within markets.

The test assumes that stations are identical. If a single equilibrium is played every day then the probability that $n_{2 m}$ stations are observed choosing action 2 on any given day is $\left(\begin{array}{l}N_{m} \\ n_{2 m}\end{array}\right)\left(\sigma_{2 m}^{*}\right)^{n_{2 m}}(1-$

\footnotetext{
${ }^{20}$ I present results from specifications which include market rank rather than the number of stations. Results using the latter variable are qualtitatively similar, but the coefficients vary more across specifications.

${ }^{21}$ I allow common ownership to affect coordination by allowing it to affect the strength of strategic incentives rather than, for example, explicitly modelling joint decision making across multiple stations.
} 
$\left.\sigma_{2 m}^{*}\right)^{N_{m}-n_{2 m}}$, the pmf for a binomial model with a single component. If two equilibria are played on different days then the probability is (5) with $E=2$, a binomial model with two components. Under the alternative of two components the model is estimated using the modified log-likelihood

$$
l^{M}\left(\lambda_{m}, \sigma_{A 2 m}^{*}, \sigma_{B 2 m}^{*}\right)=l\left(\lambda_{m}, \sigma_{A 2 m}^{*}, \sigma_{B 2 m}^{*}\right)+C \log \left(4 \lambda_{m}\left(1-\lambda_{m}\right)\right)
$$

where $l\left(\lambda_{m}, \sigma_{A 2 m}^{*}, \sigma_{B 2 m}^{*}\right)$ is the standard log-likelihood for a two component mixture model and the second term, where $C$ is a positive constant, solves the problem that some of the parameters are not identified under the null when only the standard log-likelihood is used. The test statistic is $\left.M=l^{M}\left(\widehat{\lambda_{m}}, \widehat{\sigma_{A 2 m}^{*}}, \widehat{\sigma_{B 2 m}^{*}}\right)-l^{M}\left(\frac{1}{2}, \widehat{\sigma_{2 m}^{*}}, \widehat{\sigma_{2 m}^{*}}\right)\right)$ where $\widehat{\sigma_{2 m}^{*}}$ is the choice probability for a single component mixture, and its asymptotic distribution is an equal mixture of $\chi_{0}^{2}$ and $\chi_{1}^{2}$ distributions. Chen et al. (2001) show that this test is the asymptotically most powerful under local alternatives. ${ }^{22}$

I apply the test defining the binomial actions in two different ways. The first way defines one action as having a commercial at either :50 or :55 with the other action being having no commercial at either of these times. The second way defines one action as having a commercial at :55 with the other action not having a commercial at :55. The results are reported in part (a) of Table 5, which shows the proportion of the markets where the null of a single component is rejected at the $5 \%$ level. ${ }^{23}$ The proportion of markets where the null is rejected is small (less than 6\%) in all station hours, consistent with a single equilibrium being played within each market. ${ }^{24}$

\subsubsection{Pairwise Station Correlation Test}

The MLRT test is attractive in the sense that it uses the choices of all stations within a market simultaneously, but it makes the unattractive assumption that stations within a market are identical. The remaining tests do not make this assumption.

The correlation test examines whether there is any correlation in the timing choices of pairs of

\footnotetext{
${ }^{22}$ Chen et al. (2004) present a test where a two component model can be tested against a model with $k>2$ components. This test is potentially useful for testing how many equilibria need to be allowed for.

${ }^{23}$ The test only uses the 124 markets with at least three observed stations because, as discussed in Section 4 , a two component model is not identified with fewer than three stations.

${ }^{24}$ One can also perform a joint test by adding the test statistics from each market and simulating this new statistic's asymptotic distribution. The null that there is only one equilibrium in each market cannot be rejected for any hour. The same conclusion holds for the joint version of the other tests.
} 
Table 5: Test Results for Within Market Multiple Equilibria

\begin{tabular}{lcc}
\hline \hline Action 1: & Commercial at $: 50$ or $: 55$ & Commercial at $: 55$ \\
Action 0: & No Commercial at $: 50$ or $: 55$ & No Commercial at $: 55$
\end{tabular}

(a) Modified Likelihood Ratio Test: Proportion of

Markets with Test Statistic Significant at 5\% Level (One Sided)

$\begin{array}{ccc}12-1 \mathrm{pm} & 0.035 & 0.056 \\ 4-5 \mathrm{pm} & 0.042 & 0.014 \\ 5-6 \mathrm{pm} & 0.028 & 0.007 \\ 9-10 \mathrm{pm} & 0.035 & 0.042\end{array}$

(b) Station Pairwise Correlation Test: Proportion

of Pairs With Significant Correlations at 5\% Level (Two Sided)

$\begin{array}{lll}12-1 \mathrm{pm} & 0.058 & 0.050 \\ 4-5 \mathrm{pm} & 0.047 & 0.042 \\ 5-6 \mathrm{pm} & 0.051 & 0.050 \\ 9-10 \mathrm{pm} & 0.053 & 0.049\end{array}$

(c) Station Runs Test: Proportion of

\begin{tabular}{ccc}
$12-1 \mathrm{pm}$ & 0.062 & 0.060 \\
$4-5 \mathrm{pm}$ & 0.062 & 0.050 \\
$5-6 \mathrm{pm}$ & 0.064 & 0.050 \\
$9-10 \mathrm{pm}$ & 0.048 & 0.044 \\
\hline
\end{tabular}

stations in the same market. If a market switches from one equilibrium to another then stations' strategies should change at the same time causing changes in their actions to be correlated. On the other hand, if each station uses the same strategy every day (the null hypothesis) then actions will only vary due to the iid $\varepsilon$ payoff shocks so that actions should display no time-series correlation.

The correlation test also tests the incomplete information assumption, allowing for there to be a fixed component of station preferences which does not vary from day-to-day and which is known to all stations (this will be allowed for in some of the specifications below). Under incomplete information a station's strategy is a mapping from its own $\varepsilon s$ to its timing choices. On the other hand, under complete information a station's strategy will be a mapping from all stations' $\varepsilon s$ to its timing choices so that, even if the $\varepsilon$ s are iid and strategies do not change, there should be correlations in their choices.

I implement the test using the choice definitions assumed for the MLRT test. For each pair of stations in the same market I calculate the correlation coefficient for these binary actions. ${ }^{25}$ The results

\footnotetext{
${ }^{25}$ The significance of the estimated correlation coefficient $\widehat{\rho}$ is assessed using a t-distribution with $(n-2)$ degrees of freedom where $n$ is the number of days when both stations in the pair are observed in the data.
} 
are reported in part (b) of Table 5. There are only significant correlations for a small proportion of pairs (and in these cases there is a roughly equal mix of positive and negative correlations) consistent with incomplete information and with stations using the same strategies over time.

\subsubsection{Runs Test ${ }^{26}$}

The final test is a "runs test" which looks for serial correlation in a station's own choices. A change in a station's strategy during the year should affect how frequently it makes a particular timing choice on consecutive days. The test is implemented by defining binary choices as before, ordering the data for each station by the calendar date and calculating how many runs there are of a particular choice and whether there are more or less runs than one would expect if the data was randomly ordered. ${ }^{27}$ The results are reported in part (c) of Table 5. Once again, the test statistic is only significant for a small proportion of stations.

\subsection{Two Step Estimates}

Table 6 presents the two step results. Columns (1)-(4) present estimates for each hour for specifications which allow for observable heterogeneity in non-strategic preferences $\left(\beta_{: 55}\right)$ but assume that strategic incentives $(\alpha)$ are identical across markets and symmetric across stations within a market. The estimated $\alpha$ is positive and significant at the $1 \%$ level for both drivetime hours, implying that stations do want to play commercials at the same time. Very few of the covariates affecting non-strategic preferences are statistically significant (Oldies at the $1 \%$ level for 4-5 pm and Clear Channel and ownership HHI at 5\% and 10\% levels for 5-6 pm). These coefficients are also small: for example, the Clear Channel coefficient for 5-6 pm implies that the conditional probability that a station has a commercial at :55 increases by 0.025 when the station is owned by Clear Channel compared with a mean probability of 0.50 . The lack of significant shifters of non-strategic preferences implies that "exclusion restriction" approaches to identification are likely to be ineffective.

\footnotetext{
${ }^{26}$ I woukd like to thank one of my referees for suggesting this test.

${ }^{27}$ For a $(0,1)$ action, a run is defined as a sequence of identical choices (e.g., 000 or 11). When $n_{0 s}$ is the number of $0 \mathrm{~s}$ chosen, the expected number of runs is $\frac{2 n_{0 s} n_{1 s}}{n_{0 s}+n_{1 s}}+1$ and the normal approximation to the test statistic is $z_{s}=$ $\frac{r_{s}-\left(\frac{2 n_{0 s} n_{1 s}}{n_{0 s}+n_{1 s}}+1\right)}{\sqrt{\frac{2 n_{0 s} n_{1 s}\left(2 n_{0 s} n_{1 s}-\left(n_{0 s}+n_{1 s}\right)\right.}{\left(n_{0 s}+n_{1 s}\right)^{2}\left(n_{0 s}+n_{1 s}-1\right)}}}$ where $r_{s}$ is the number of runs.
} 
Table 6: Two Step Estimates

\begin{tabular}{|c|c|c|c|c|c|c|c|c|c|c|}
\hline $\begin{array}{l}\text { Hour } \\
\underline{\text { B. }{ }_{55} \text { Coefficients }}\end{array}$ & $\begin{array}{c}(1) \\
4-5 \mathrm{pm}\end{array}$ & $\begin{array}{c}(2) \\
5-6 \mathrm{pm}\end{array}$ & $\begin{array}{c}(3) \\
12-1 \mathrm{pm}\end{array}$ & $\begin{array}{c}(4) \\
9-10 \mathrm{pm}\end{array}$ & $\begin{array}{c}5) \\
4-5 \mathrm{pm}\end{array}$ & $\begin{array}{c}6) \\
5-6 \mathrm{pm}\end{array}$ & $\begin{array}{c}(7) \\
12-1 \mathrm{pm}\end{array}$ & $\begin{array}{c}(8) \\
9-10 \mathrm{pm}\end{array}$ & $\begin{array}{c}(9) \\
4-5 \mathrm{pm}\end{array}$ & $\begin{array}{c}(10) \\
5-6 \mathrm{pm}\end{array}$ \\
\hline Constant & $\begin{array}{c}1.921 \\
(1.426)\end{array}$ & $\begin{array}{l}-0.065 \\
(1.234)\end{array}$ & $\begin{array}{c}2.278 \\
(1.833)\end{array}$ & $\begin{array}{c}0.099 \\
(2.564)\end{array}$ & $\begin{array}{c}2.794^{\star * *} \\
(1.038)\end{array}$ & $\begin{array}{c}0.217 \\
(0.924)\end{array}$ & $\begin{array}{c}2.723 \\
(10.595)\end{array}$ & $\begin{array}{c}0.340 \\
(18.850)\end{array}$ & $\begin{array}{c}3.097 \\
(1.785)\end{array}$ & $\begin{array}{c}0.129 \\
(1.552)\end{array}$ \\
\hline Country & $\begin{array}{c}0.139 \\
(0.088)\end{array}$ & $\begin{array}{c}0.032 \\
(0.101)\end{array}$ & $\begin{array}{l}-0.026 \\
(0.067)\end{array}$ & $\begin{array}{c}0.322^{* * *} \\
(0.102)\end{array}$ & $\begin{array}{l}0.130^{*} \\
(0.074)\end{array}$ & $\begin{array}{l}0.008 \\
(0.084)\end{array}$ & $\begin{array}{l}-0.063 \\
(0.072)\end{array}$ & $\begin{array}{c}0.507^{\star * *} \\
(0.132)\end{array}$ & $\begin{array}{l}0.118 \\
(0.058)\end{array}$ & $\begin{array}{l}0.008 \\
(0.082)\end{array}$ \\
\hline Rock & $\begin{array}{l}-0.023 \\
(0.071)\end{array}$ & $\begin{array}{l}-0.013 \\
(0.077)\end{array}$ & $\begin{array}{c}-0.418^{* * *} \\
(0.072)\end{array}$ & $\begin{array}{c}-0.679^{* * *} \\
(0.092)\end{array}$ & $\begin{array}{l}-0.055 \\
(0.065)\end{array}$ & $\begin{array}{l}-0.015 \\
(0.052)\end{array}$ & $\begin{array}{c}-0.532^{* * *} \\
(0.149)\end{array}$ & $\begin{array}{c}-0.745^{* * *} \\
(0.172)\end{array}$ & $\begin{array}{l}-0.065 \\
(0.093)\end{array}$ & $\begin{array}{l}-0.006 \\
(0.063)\end{array}$ \\
\hline Urban & $\begin{array}{c}0.101 \\
(0.088)\end{array}$ & $\begin{array}{l}-0.076 \\
(0.087)\end{array}$ & $\begin{array}{c}-0.278^{\star * *} \\
(0.071)\end{array}$ & $\begin{array}{c}-0.704^{\star * *} \\
(0.118)\end{array}$ & $\begin{array}{c}0.087 \\
(0.089)\end{array}$ & $\begin{array}{l}-0.122 \\
(0.083)\end{array}$ & $\begin{array}{c}-0.355^{\star \star \star *} \\
(0.107)\end{array}$ & $\begin{array}{c}-0.719^{* \star *} \\
(0.155)\end{array}$ & $\begin{array}{l}0.066 \\
(0.090)\end{array}$ & $\begin{array}{l}-0.110 \\
(0.092)\end{array}$ \\
\hline $\begin{array}{l}\text { Station's Share of } \\
\text { Radio Listenership }\end{array}$ & $\begin{array}{l}-0.482 \\
(0.519)\end{array}$ & $\begin{array}{l}0.025 \\
(0.482)\end{array}$ & $\begin{array}{c}0.527 \\
(0.414)\end{array}$ & $\begin{array}{c}0.263 \\
(0.732)\end{array}$ & $\begin{array}{l}-0.874 \\
(0.318)\end{array}$ & $\begin{array}{c}0.142 \\
(0.327)\end{array}$ & $\begin{array}{c}0.397 \\
(0.506)\end{array}$ & $\begin{array}{c}0.615 \\
(0.730)\end{array}$ & $\begin{array}{l}-0.830 \\
(0.055)\end{array}$ & $\begin{array}{l}0.211 \\
(0.427)\end{array}$ \\
\hline Market Rank (/100) & $\begin{array}{c}0.078 \\
(0.102)\end{array}$ & $\begin{array}{c}0.052 \\
(0.091)\end{array}$ & $\begin{array}{l}-0.014 \\
(0.088)\end{array}$ & $\begin{array}{c}0.066 \\
(0.133)\end{array}$ & $\begin{array}{l}0.045 \\
(0.112)\end{array}$ & $\begin{array}{l}0.059 \\
(0.108)\end{array}$ & $\begin{array}{c}0.024 \\
(0.515)\end{array}$ & $\begin{array}{c}0.005 \\
(1.002)\end{array}$ & $\begin{array}{l}0.035 \\
(0.109)\end{array}$ & $\begin{array}{l}0.024 \\
(0.083)\end{array}$ \\
\hline Owner: Clear Channel & $\begin{array}{l}0.084 \\
(0.060)\end{array}$ & $\begin{array}{l}0.101^{* *} \\
(0.043)\end{array}$ & $\begin{array}{l}-0.049 \\
(0.062)\end{array}$ & $\begin{array}{l}0.151^{* *} \\
(0.062)\end{array}$ & $\begin{array}{l}0.105^{\star *} \\
(0.053)\end{array}$ & $\begin{array}{l}0.060 \\
(0.047)\end{array}$ & $\begin{array}{l}-0.028 \\
(0.050)\end{array}$ & $\begin{array}{c}0.139^{* * *} \\
(0.036)\end{array}$ & $\begin{array}{l}0.095^{*} \\
(0.050)\end{array}$ & $\begin{array}{l}0.070 \\
(0.440)\end{array}$ \\
\hline Owner: Infinity & $\begin{array}{l}-0.026 \\
(0.080)\end{array}$ & $\begin{array}{c}0.019 \\
(0.095)\end{array}$ & $\begin{array}{l}-0.117 \\
(0.091)\end{array}$ & $\begin{array}{l}0.184^{*} \\
(0.106)\end{array}$ & $\begin{array}{l}-0.094 \\
(0.066)\end{array}$ & $\begin{array}{l}-0.039 \\
(0.063)\end{array}$ & $\begin{array}{c}-0.124^{\star *} \\
(0.062)\end{array}$ & $\begin{array}{c}0.197^{\star * *} \\
(0.072)\end{array}$ & $\begin{array}{l}-0.105 \\
(0.071)\end{array}$ & $\begin{array}{l}-0.018 \\
(0.089)\end{array}$ \\
\hline Ownership HHI & $\begin{array}{l}-0.093 \\
(0.420)\end{array}$ & $\begin{array}{l}-0.489^{*} \\
(0.280)\end{array}$ & $\begin{array}{l}-0.484 \\
(0.388)\end{array}$ & $\begin{array}{c}0.317 \\
(0.576)\end{array}$ & $\begin{array}{c}0.169 \\
(0.376)\end{array}$ & $\begin{array}{l}-0.629^{*} \\
(0.348)\end{array}$ & $\begin{array}{l}-0.797 \\
(1.032)\end{array}$ & $\begin{array}{c}0.965 \\
(1.130)\end{array}$ & $\begin{array}{c}0.183 \\
(0.610)\end{array}$ & $\begin{array}{l}-0.619^{* *} \\
(0.325)\end{array}$ \\
\hline Listenership Asymmetry & $\begin{array}{c}0.008 \\
(0.146)\end{array}$ & $\begin{array}{l}-0.082 \\
(0.105)\end{array}$ & $\begin{array}{l}-0.280 \\
(0.161)\end{array}$ & $\begin{array}{c}0.086 \\
(0.193)\end{array}$ & $\begin{array}{c}0.041 \\
(0.158)\end{array}$ & $\begin{array}{l}-0.170 \\
(0.144)\end{array}$ & $\begin{array}{l}-0.158 \\
(0.373)\end{array}$ & $\begin{array}{l}-0.201 \\
(0.415)\end{array}$ & $\begin{array}{c}0.022 \\
(0.166)\end{array}$ & $\begin{array}{l}-0.171 \\
(0.165)\end{array}$ \\
\hline $\begin{array}{l}\text { Market Random Effect } \\
\text { Std Deviation } \\
\text { Station Random Effect } \\
\text { Std Deviation }\end{array}$ & - & - & - & - & $\begin{array}{c}1.20 \mathrm{E}-08 \\
(3.42 \mathrm{E}-09) \\
0.830^{\star * *} \\
(0.039)\end{array}$ & $\begin{array}{c}5.30 \mathrm{E}-11 \\
(1.62 \mathrm{E}-10) \\
0.842^{* * *} \\
(0.046)\end{array}$ & $\begin{array}{c}4.00 \mathrm{E}-06 \\
(2.58 \mathrm{E}-05) \\
0.817^{\star * *} \\
(0.291)\end{array}$ & $\begin{array}{c}6.94 \mathrm{E}-06 \\
(2.98 \mathrm{E}-05) \\
1.154^{\star * *} \\
(0.301)\end{array}$ & $\begin{array}{c}2.55 \mathrm{E}-07 \\
(6.09 \mathrm{E}-07) \\
0.821^{\star * *} \\
(0.039)\end{array}$ & $\begin{array}{c}7.84 \mathrm{E}-06 \\
(2.10 \mathrm{E}-05) \\
0.836^{\star * *} \\
(0.048)\end{array}$ \\
\hline Strategic Incentive ( $\alpha$ ) coeffic & & & & & & & & & & \\
\hline Same Format & - & - & - & - & $\begin{array}{l}-0.286 \\
(0.232)\end{array}$ & $\begin{array}{l}-0.240 \\
(0.308)\end{array}$ & $\begin{array}{l}-0.395 \\
(0.246)\end{array}$ & $\begin{array}{c}0.624^{* * *} \\
(0.183)\end{array}$ & $\begin{array}{l}-0.183 \\
(0.280)\end{array}$ & $\begin{array}{l}-0.176 \\
(0.322)\end{array}$ \\
\hline Log-likelihood & -18817.0 & -18370.9 & -19210.1 & -17101.4 & -17736.9 & -17330.6 & -17239.8 & -15328 & -17726.8 & -17324.1 \\
\hline Number of Station-Hours & 27,889 & 27,574 & 26,548 & 25,669 & 27,889 & 27,574 & 26,548 & 25,669 & 27,889 & 27,574 \\
\hline
\end{tabular}

Note: Standard error in parentheses, calculated using a bootstrap which resamples markets. 100 repetitions used for columns 1-8, 25 for columns 9-10.

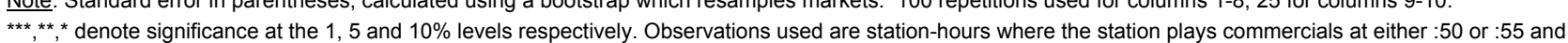

more than one station is observed in the market. 
For the non-drivetime hours (columns (3) and (4)) the strategic incentive coefficients are positive but statistically insignificant. The difference between the drivetime and non-drivetime results is consistent with greater listener switching during drivetime strengthening strategic incentives. The standard errors on $\alpha$ in columns (3) and (4) are similar to those in columns (1) and (2) suggesting that this does not result from a lack of variation in the behavior of other stations across markets (as could happen if the same equilibrium was played in every market). Stations in different formats differ in their non-strategic preferences outside drivetime. ${ }^{28}$

The specifications in columns (5)-(8) allow for persistent unobserved market and station heterogeneity in stations' non-strategic preferences and for stations to be more concerned about how they time their commercials relative to stations in their own format. The heterogeneity enters as two normally distributed random effects. The station random effects allow for an individual station to persistently make a particular timing choice while the market heterogeneity allows a non-strategic explanation for why stations in the same market make the same timing choice. The within-format strategic effect is allowed for by including an additional term in the model which corresponds to the term in the inner brackets of (8) calculated only using stations in the same market-format.

While persistent station unobserved heterogeneity is important in all hours, the models which fit the data best have essentially no unobserved market heterogeneity in non-strategic preferences. The "all station" strategic incentives for drivetime hours remain significant. A legitimate concern is that this result partly reflects the restrictive parametric form assumed for the market heterogeneity. It is worth noting however that for the non-drivetime hours the problem of separately identifying strategic incentives and market-heterogeneity results in much larger standard errors on many of the variables, including the all station strategic incentive, while this does not happen in drivetime hours where strategic effects appear to be much stronger.

The within-format strategic incentive is small and statistically insignificant in both drivetime hours implying that, at least when it comes to timing decisions, music stations interact in a fairly symmetric

\footnotetext{
${ }^{28}$ In particular, Adult Contemporary, Oldies and Country stations are more likely to have later commercials. This may be explained by these stations, which tend to have older listeners than stations in some of the other music formats, carrying news headlines at the top of the hour. If listeners will not switch because they want to hear the headlines then it would be a good strategy for stations to play commercials right before the headlines. The estimated strategic incentives imply that relatively few CHR, Rock and Urban stations try to copy these strategies outside drivetime.
} 
way. This finding is plausible if listeners switch primarily between preset stations and tend to preset one station in each format. ${ }^{29}$ The format strategic incentive for 9-10 pm is significant but it only offsets the negative and insignificant all station coefficient.

Columns (9) and (10) allow the all station strategic incentive to vary with observable market characteristics (market rank, ownership concentration and listenership asymmetry) during drivetime. The positive market rank coefficients are consistent with there being more coordination in smaller markets but they are only weakly significant. The NFXP results will support the suggestion that this may be due to the incomplete sample biasing the estimates of $\alpha$ in smaller markets. None of the ownership or listenership asymmetry interaction coefficients are significant.

I have also estimated several specifications whose results are not reported. One of these allows for a non-linear strategic incentive by including the square of the variable which multiples the $\alpha$ coefficient in (8). Nonlinearities might arise if a station has an incentive to play its commercials at a different time, to attract a large number of switchers, once the vast majority of other stations are coordinating. The coefficients on the squared term in specification like columns (1)-(4) are all statistically insignificant (e.g. 0.417 (1.234) for 4-5 pm and -0.586 (0.844) for 5-6 pm) with the other coefficients almost unchanged. This result could be explained by linearity being the correct model or by the variation in other stations' strategies being too limited to identify more complicated effects.

\subsection{NFXP Estimates and the Strength of Coordination Incentives}

The simplest NFXP specification, whose results are reported in columns (1)-(4) of Table 7, assumes that there is no unobserved heterogeneity in either $\beta_{: 55}$ or $\alpha$. I allow at most one observable stationspecific variable to affect non-strategic preferences. Based on the two-step results, this variable is an Oldies dummy for 4-5 pm and a dummy for CHR, Rock and Urban stations outside drivetime. ${ }^{30}$

The estimates of $\alpha$ are positive and significant for both of the drivetime hours, implying that

\footnotetext{
${ }^{29}$ For example, I have News, Sports, Adult Contemporary, Country and Rock stations preset and if I want to skip a commercial then I would usually switch between these stations. Of course, several AC may have competed directly on programming (but not timing) to be my AC preset choice. Arbitron data supports the suggestion that stations share listeners as much across formats as within formats. For example, in Fall 2002 there were 6 Rock and 9 non-Rock home contemporary music stations in Boston. On average 15.6\% of the listeners to a Rock station listened to each of the other Rock stations and $15.3 \%$ of the listeners to a Rock station listened to each of the non-Rock stations ("the cume duplication" tables in Arbitron (2003)).

${ }^{30} \mathrm{~A}$ few stations change formats during 2001. When estimating the model I treat stations as being in their Spring 2001 formats throughout the year.
} 
Model 1

Hour

\section{$\beta_{.55}$ coefficients}

Constant

Format Variable

(see notes for definition)

Station Random Effect, Std Deviation

Strategic Incentives ( $\alpha$ )

Constant

Market Rank (Linear Effect)

Market Rank $\geq 50$

Market Rank $\geq 100$

Ownership $\mathrm{HHI}$

(normalized mean 0 , std deviation 1 )

Market Random Effect, Std. Deviation

Probability that :50 or :55 are chosen

$\beta_{1 \text { or } 2}$

Station Random Effect, Std Deviation

Market Random Effect, Std Deviation

\section{Equilibrium Selection}

$(\mathrm{N}=$ not identified when parameters do not

support multiple equilibria for any simulation

draws)

4-5 pm Choosing:50 or 55

0.001

$(0.001)$

0.005
$(0.008)$

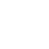

Station and Market Heterogeneity in Probabilities of

Listenership Asymmetry

(normalized mean 0 , std deviation 1 )

5-6 pm $\quad 12-1 \mathrm{pm} \quad 9-10 \mathrm{pm}$

$\begin{array}{ccc}0.002^{* * *} & 0.199^{* * *} & 0.560^{* * *} \\ (0.000) & (0.009) & (0.008) \\ \mathrm{N} / \mathrm{A} & -0.417^{* * *} & -0.932^{\star * *} \\ & (0.015) & (0.010)\end{array}$

(0.010)

$(0.004)$

$(0.004)$
0.005

0.005
$(0.033)$

Adds

Model 2

Adds Market Heterogeneity in Strategic Incentives

\begin{tabular}{|c|c|c|c|c|c|c|c|c|c|}
\hline $\begin{array}{c}3.304^{* * *} \\
(0.006)\end{array}$ & $\begin{array}{c}3.404^{* * *} \\
(0.006)\end{array}$ & $\begin{array}{c}1.818^{* * *} \\
(0.104)\end{array}$ & $\begin{array}{c}0.476^{\star * *} \\
(0.123)\end{array}$ & $\begin{array}{c}0.106 \\
(0.261)\end{array}$ & $\begin{array}{c}0.200 \\
(0.325)\end{array}$ & $\begin{array}{c}0.125 \\
(0.308)\end{array}$ & $\begin{array}{c}0.025 \\
(0.359)\end{array}$ & $\begin{array}{c}0.107 \\
(0.118)\end{array}$ & $\begin{array}{c}0.706^{\star \star *} \\
(0.176)\end{array}$ \\
\hline- & - & - & - & $\begin{array}{c}0.021 \\
(0.139)\end{array}$ & $\begin{array}{c}0.010 \\
(0.171)\end{array}$ & $\begin{array}{c}0.024 \\
(0.860)\end{array}$ & $\begin{array}{c}0.003 \\
(0.631)\end{array}$ & $\begin{array}{c}0.021 \\
(0.338)\end{array}$ & $\begin{array}{c}0.035 \\
(0.277)\end{array}$ \\
\hline - & - & - & - & $\begin{array}{l}1.205^{\star \star \star \star} \\
(0.119)\end{array}$ & $\begin{array}{l}1.741^{* * *} \\
(0.322)\end{array}$ & $\begin{array}{c}0.119 \\
(0.444)\end{array}$ & $\begin{array}{c}0.020 \\
(0.227)\end{array}$ & $\begin{array}{l}1.214^{* * *} \\
(0.236)\end{array}$ & $\begin{array}{c}1.790^{\star \star * *} \\
(0.187)\end{array}$ \\
\hline - & - & - & - & $\begin{array}{l}1.563^{\star \star \star} \\
(0.171)\end{array}$ & $\begin{array}{l}1.177^{* * *} \\
(0.102)\end{array}$ & $\begin{array}{c}0.252 \\
(0.437)\end{array}$ & $\begin{array}{c}0.011 \\
(0.332)\end{array}$ & $\begin{array}{c}1.574^{* * *} \\
(0.194)\end{array}$ & $\begin{array}{c}0.855^{\star * *} \\
(0.160)\end{array}$ \\
\hline - & - & - & - & $\begin{array}{c}0.099^{\star * \star} \\
(0.021)\end{array}$ & $\begin{array}{c}0.101^{* \star *} \\
(0.020)\end{array}$ & $\begin{array}{c}0.076 \\
(0.175)\end{array}$ & $\begin{array}{c}0.008 \\
(0.118)\end{array}$ & $\begin{array}{c}0.100 \\
(0.069)\end{array}$ & $\begin{array}{c}-0.203^{\star * *} \\
(0.044)\end{array}$ \\
\hline- & - & - & - & $\begin{array}{c}0.052 \\
(0.050)\end{array}$ & $\begin{array}{c}0.053 \\
(0.024)\end{array}$ & $\begin{array}{c}0.053 \\
(0.150)\end{array}$ & $\begin{array}{c}0.011 \\
(0.149)\end{array}$ & $\begin{array}{c}0.052 \\
(0.074)\end{array}$ & $\begin{array}{l}-0.055 \\
(0.047)\end{array}$ \\
\hline - & - & - & - & $\begin{array}{c}2.359^{\star \star *} \\
(0.201)\end{array}$ & $\begin{array}{c}1.183^{\star \star \star} \\
(0.050)\end{array}$ & $\begin{array}{c}1.838^{\star * *} \\
(0.168)\end{array}$ & $\begin{array}{c}2.450^{\star \star \star} \\
(0.168)\end{array}$ & $\begin{array}{c}2.165^{\star \star \star} \\
(0.090)\end{array}$ & $\begin{array}{c}0.878^{\star \star *} \\
(0.051)\end{array}$ \\
\hline $0.302^{\star \star \star}$ & $0.312^{\star \star \star}$ & $0.139^{* * *}$ & $0.047^{* * *}$ & $0.306^{\star * *}$ & $0.294^{* * *}$ & $0.217^{* * *}$ & $0.200^{* * *}$ & $0.309^{* * *}$ & $0.269^{\star \star \star}$ \\
\hline$(0.009)$ & $(0.005)$ & (0.009) & $(0.010)$ & $(0.018)$ & $(0.009)$ & $(0.011)$ & $(0.013)$ & $(0.006)$ & $(0.007)$ \\
\hline $0.197^{\star \star \star}$ & $0.457^{\star \star \star *}$ & $0.257^{* * *}$ & $0.260^{* * *}$ & 0.002 & $0.341^{* * *}$ & $0.254^{* * *}$ & $0.237^{* * *}$ & 0.002 & $0.025^{\star \star}$ \\
\hline$(0.012)$ & $(0.006)$ & $(0.013)$ & $(0.013)$ & $(0.023)$ & $(0.007)$ & $(0.012)$ & $(0.011)$ & $(0.010)$ & (0.009) \\
\hline $\begin{array}{c}0.397^{\star \star \star} \\
(0.014)\end{array}$ & $\begin{array}{l}0.707^{\star * \star} \\
(0.009)\end{array}$ & $\begin{array}{c}0.250^{* * *} \\
(0.009)\end{array}$ & $\begin{array}{l}0.319^{\star * \star} \\
(0.011)\end{array}$ & $\begin{array}{c}0.344^{* * *} \\
(0.014)\end{array}$ & $\begin{array}{c}0.647^{* * *} \\
(0.014)\end{array}$ & $\begin{array}{c}0.294^{* * *} \\
(0.011)\end{array}$ & $\begin{array}{c}0.371^{* * *} \\
(0.016)\end{array}$ & $\begin{array}{l}0.349^{* * \star} \\
(0.007)\end{array}$ & $\begin{array}{c}0.402^{* \star *} \\
(0.008)\end{array}$ \\
\hline $\begin{array}{c}0.475^{\star * *} \\
(0.018)\end{array}$ & $\begin{array}{c}0.524^{* * *} \\
(0.068)\end{array}$ & $\mathrm{NI}$ & $\mathrm{NI}$ & $\begin{array}{c}0.520^{* * *} \\
(0.088)\end{array}$ & $\begin{array}{c}0.400^{\star * *} \\
(0.084)\end{array}$ & $\begin{array}{c}0.632 \\
(0.596)\end{array}$ & $\begin{array}{c}0.511 \\
(0.369)\end{array}$ & $\begin{array}{c}0.524^{* * *} \\
(0.135)\end{array}$ & $\begin{array}{l}0.498^{\star *} \\
(0.220)\end{array}$ \\
\hline
\end{tabular}

Log-likelihood

Model 3

Adds Station Heterogeneity

in Preferences for :55

4-5 pm 5-6 pm

$0.001 \quad 0.004$

$(0.009) \quad(0.004)$

$(0.016)$

$0.451^{* * *} \quad 0.412^{* *}$

$(0.009) \quad(0.009)$

Number of Station-Hours

50,227

50,103

50,365

49,644

$-52,587.30$

50,227

$-52,307.10-52,698.50$

50,103

50,365

$-51,101.40$

$-52,326,40$

50,227

$-51,804.00$

Notes: Standard errors in parantheses ${ }^{* * * * * *}{ }^{*}$ denote statistic significance at the 1,5 and $10 \%$ levels respectively. Estimation by simulated maximum likelihood using a Nelder-Mead search algorithm.

Number of simulations per station/market=100 for Model 1 and $=50$ for Models 2 and 3 . Format variable: for $4-5$ pm an Oldies dummy, for $12-1 \mathrm{pm}$ and $9-10 \mathrm{pm}$ a dummy for $\mathrm{CHR}$, Rock

and Urban stations. 
stations want to play commercials at the same time, and, consistent with mismeasurement affecting the two-step estimates, the coefficients are larger than in columns (1) and (2) of Table $6 . \quad \alpha$ is also estimated to be positive and significant outside drivetime although the incentive to coordinate is too small to support multiple equilibria (so the $\lambda$ parameters are not identified).

Columns (5)-(8) show specifications with both observable and unobservable heterogeneity in the strength of strategic incentives $\left(\alpha_{m}=X_{m} \alpha+\eta_{\alpha}\right.$ where $\left.\eta_{\alpha} \sim N\left(0, \gamma_{\alpha}^{2}\right)\right)$. As well as the market rank group dummies I include a linear market rank variable but its coefficient is always small and insignificant. The pattern that coordination incentives are stronger in smaller markets during drivetime is more significant than in the two-step results and the coefficients are similar across the drivetime hours. The listenership asymmetry coefficients are also positive and significant during drivetime but the coefficients are quite small (the standard deviation of the variable is normalized to 1 for the NFXP estimates). There is significant unobserved heterogeneity in strategic incentives across markets in all hours, but during drivetime differences in market size explains quite a lot of the total variation.

Columns (9) and (10) allow for persistent unobserved station heterogeneity in non-strategic preferences. This heterogeneity is assumed to be normally distributed and to be observed by all stations when they choose their timing strategies. Consistent with the two-step results, this type of heterogeneity is clearly significant, but most of the other coefficients remain largely unchanged. An exception is the listenership asymmetry coefficient for 5-6 pm which becomes negative: therefore the Model 2 results for this variable, while consistent with the overall finding that stations coordinate on timing during drivetime, should be treated with caution. A disappointing feature of the results is that ownership concentration is not significant in any of the specifications.

The strength of strategic incentives associated with different values of $\alpha$ can be illustrated using an example. I initially abstract away from heterogeneity in non-strategic preferences. Suppose that there is a market where all stations choose to have a commercial in one of the two time slots $(: 50$ or :55) with probability 0.6 (close to the drivetime averages). I analyze how different values of $\alpha$ affect station best response probabilities and equilibrium strategies for stations playing commercials at one of these times. The effect of $\alpha$ on a station's best response probability of choosing :55 is measured by changing the conditional probability that other stations choose :55 from 0 to 1 (so the unconditional 
probability that they choose :55 changes from 0 to 0.6 ). The second column of Table 8 reports the change in the best response. The third column reports the associated stable Bayesian Nash equilibrium strategies. An entry of "(0.6,0.4)" means that there is one equilibrium where stations choose :55 with conditional probability 0.6 and $: 50$ with conditional probability 0.4 and another equilibrium where these probabilities are reversed. To interpret the table, recall that the estimated drivetime value of $\alpha$ for 4-5 pm for NFXP Model 1 is 3.3 and that the mean values of $\alpha$ for the three market size groups for NFXP Model 2 are 0.04 (markets ranked 1-49), 1.34 (50-99) and 2.9 (above 100) with standard deviation 2.36. The values of $\alpha$ are very similar for Model 3 and they are broadly similar for 5-6 pm.

Even for quite low values of $\alpha$, a station's best response is quite sensitive to the strategies of other stations: for example, when $\alpha=1$ changes in the strategies of other stations can change a station's optimal conditional choice probability by almost 0.3 . However, $\alpha=1$ results in no equilibrium coordination in the sense that each station chooses each time with equal probability. The logic for this result is quite simple (and can be seen graphically by centering the reaction functions in Figure $3(\mathrm{a}))$ : if one station increased its probability of choosing :55, the best response of other stations would be to increase their probabilities but by less, and the iteration of best responses would return stations to making each choice with equal probability. Therefore observing that commercials do not overlap that much does not imply that a station would not have quite strong incentives to coordinate if other stations played them at the same time. As $\alpha$ increases above 3, multiple equilibria can be supported and the stable equilibria involve greater overlap of commercials. For example, if $\alpha=3.5$ (a plausible value in smaller markets during drivetime) an equilibrium can be supported where stations choose :55 with probability 0.685 , so that the probability that two stations play commercials at the same time is $14 \%$ higher than if they choose each time with equal probability.

As already mentioned, there are externalities in the timing game which reduce equilibrium coordination. The last column of Table 8 quantifies the equilibrium effects of these externalities by showing the strategies which would maximize stations' expected joint payoffs. The calculation, which follows one presented by Brock and Durlauf (2001), assumes that the $\varepsilon$ s remain private information. For low levels of $\alpha$, joint payoff-maximizing strategies still involve no coordination. However, as $\alpha$ increases strategies rapidly shift to involving much more coordination than equilibrium strategies, with almost 
Table 8: Effect of Different Coordination Incentives on Individual and Equilibrium Strategies

\begin{tabular}{cccc}
\hline \hline \multicolumn{2}{c}{$\begin{array}{c}\text { Best Response Incentive } \\
\text { Change in Choice Probability }\end{array}$} & $\begin{array}{c}\text { Bayesian Nash Equilibrium } \\
\text { Strategies }\end{array}$ & $\begin{array}{c}\text { Joint Payoff Maximizing } \\
\text { Strategies }\end{array}$ \\
\hline 0 & 0 & $(0.5,0.5)$ & $(0.5,0.5)$ \\
0.5 & 0.149 & $(0.5,0.5)$ & $(0.5,0.5)$ \\
1 & 0.291 & $(0.5,0.5)$ & $(0.5,0.5)$ \\
1.5 & 0.422 & $(0.5,0.5)$ & $(0.5,0.5)$ \\
2 & 0.537 & $(0.5,0.5)$ & $(0.829,0.171)$ \\
2.5 & 0.635 & $(0.5,0.5)$ & $(0.929,0.071)$ \\
3 & 0.716 & $(0.5,0.5)$ & $(0.966,0.034)$ \\
3.35 & 0.764 & $(0.561,0.439)$ & $(0.979,0.021)$ \\
3.4 & 0.770 & $(0.620,0.380)$ & $(0.981,0.019)$ \\
3.5 & 0.782 & $(0.685,0.315)$ & $(0.983,0.017)$ \\
3.75 & 0.809 & $(0.776,0.224)$ & $(0.988,0.012)$ \\
4 & 0.834 & $(0.829,0.177)$ & $(0.991,0.009)$ \\
4.5 & 0.874 & $(0.893,0.107)$ & $(0.995,0.005)$ \\
\hline \hline
\end{tabular}

all stations making the same timing choice. One implication of this pattern is that even if stations are trying to play their commercials at the same time they may well be coordinating much less than they would if they maximized the joint value of their commercial time.

This paper has emphasized the role that multiple equilibria can play in the identification of strategic incentives. It is therefore interesting to examine how many simulated markets have multiple equilibria at the estimated parameters. This shown in Table 9 for the models estimated using data from 12-1 pm and 4-5 pm. In NFXP Model $1 \alpha$ is constant across markets so that the existence of multiple equilibria depends only on the proportion of stations having commercials at 4-5 pm or 5-6 pm. For 4-5 pm, this proportion is high enough to support multiple equilibria in $34 \%$ of simulated markets, while $\alpha$ is too low to support multiple equilibria in any simulated markets for $12-1 \mathrm{pm}$. Models 2 and 3 allow for observed and unobserved heterogeneity in $\alpha$ across markets: for 4-5 pm multiple equilibria are supported in many of the simulated smaller markets, but they are only supported in larger markets which receive a high $\eta_{\alpha}$ draw.

Fewer simulated markets have multiple equilibria in Model 3 even though the parameters are similar to Model 2. This is because of persistent heterogeneity in non-strategic preferences. If a few stations have a strong preference for playing commercials at :55 then, unless $\alpha$ is exceptionally high, an equilibrium where other stations play commercials at :50 cannot be supported. On the other hand, when some stations have strong preferences to play their commercials at a particular time, other 
Table 9: Proportion of Simulated Markets with Multiple Equilibria

\begin{tabular}{cccc}
\hline \hline NFXP Model & Hour & Markets & $\begin{array}{c}\text { Proportion of Simulated Markets with } \\
\text { Multiple Equilibria at Estimated Parameters }\end{array}$ \\
\hline 1 & $4-5 \mathrm{pm}$ & All & 0.34 \\
2 & $4-5 \mathrm{pm}$ & Rank 1-49 & 0.07 \\
2 & $4-5 \mathrm{pm}$ & Rank 50-99 & 0.17 \\
2 & $4-5 \mathrm{pm}$ & Rank 100+ & 0.39 \\
3 & $4-5 \mathrm{pm}$ & Rank 1-49 & 0.03 \\
3 & $4-5 \mathrm{pm}$ & Rank 50-99 & 0.10 \\
3 & $4-5 \mathrm{pm}$ & Rank 100+ & 0.27 \\
& & & 0 \\
1 & $12-1 \mathrm{pm}$ & All & 0.01 \\
2 & $12-1 \mathrm{pm}$ & Rank 1-49 & 0.02 \\
2 & $12-1 \mathrm{pm}$ & Rank 50-99 & 0.03 \\
\hline
\end{tabular}

stations will also choose to play their commercials then. Therefore, while Model 3 implies that multiple equilibria can be supported in fewer markets than the other models, it does not imply less equilibrium coordination on the timing of commercials.

\section{Conclusion}

The paper was motivated by the observation that advertisers and stations may have conflicting incentives about when commercials should be played. My finding that stations do try to coordinate on timing, even though this may reduce their measured audiences, suggests that there are mechanisms which align their incentives with those of advertisers. Perhaps the most plausible mechanism is that advertisers are able to measure the effectiveness of their advertising on different stations, by seeing how demand for advertised products changes, and that they reward the stations which give them the highest returns by placing more commercials on them in the future.

While I find that stations do coordinate on timing, their commercials still do not overlap perfectly in equilibrium. One cause of imperfect coordination is that it is simply quite hard for stations to play commercials at precise times because they have to fit commercials in or around other types of programming. This issue is more relevant for radio than television which makes more use of prerecorded and carefully scripted programming. It is also possible that coordination is imperfect partly because incentives are not fully aligned. For example, a retailer who experiences only a small increase 
in sales may not be certain whether listeners avoided the commercial or whether the ad it provided was not persuasive. From this perspective, it would be interesting to know how the recent decision of Nielsen Media Research to release information on the viewership of commercials on television stations separately from the viewership of other programming will affect timing strategies.

The paper has also made a methodological contribution by investigating how multiple equilibria can aid the identification of strategic incentives. Assuming that the mixture of equilibrium strategies in the data can be identified, having multiple equilibria will always be helpful for identification for the simple reason that it provides additional sets of equations which the parameters have to satisfy. That having been said, I would certainly not advocate basing an estimation strategy solely on the possible existence of multiple equilibria if other sources of variation are available, because the existence of multiple equilibria may be more sensitive to the assumed model specification. At the very least, if one does rely on multiple equilibria then one should investigate the robustness of one's results to allowing for different types of heterogeneity as I have done here.

However, even if valid exclusion restrictions can be made it is not appropriate to ignore the possibility that multiple equilibria exist in the data. ${ }^{31}$ The existence of multiple equilibria will lead to the relationship between observable characteristics and a firm's expectations about how other firms behave to be a correspondance rather than a function. Inappropriately assuming that a function can describe this relationship will lead to biased estimates even if any assumed exclusion restrictions are valid. For this reason, I believe that it is important that we develop to tests to identify whether the common assumption that "only a single equilibrium is played in the data" is really correct, and I hope that this paper encourages further research in this direction.

\footnotetext{
${ }^{31}$ Note that commonly used strategies such as estimating a model assuming that there is a single equilibrium and showing that only a single equilibrium can be found at the estimated parameters is not the same as allowing for multiple equilibria for the simple reason that if they were allowed for during estimation then the parameter estimates might be different.
} 


\section{References}

[1] Abernethy, Avery M. (1991), "Differences Between Advertising and Program Exposure for Car Radio Listening", Journal of Advertising Research, 31(2), 33-42

[2] Ackerberg, Daniel A. and Gautam Gowrisankaran (2006), "Quantifying Equilibrium Network Externalities in the ACH Banking Industry", RAND Journal of Economics, 37(3), 738-761

[3] Aguirregabiria, Victor and Pedro Mira (2007), "Sequential Estimation of Dynamic Discrete Games", Econometrica, 75(1), 1-53

[4] Andrews, Donald W.K., Steven T. Berry and Panle Jia (2004), "Confidence Regions for Parameters in Discrete Games with Multiple Equilibria, with An Application to Discount Chain Store Location", mimeo, Yale University

[5] Arbitron Company and Edison Media Research (1999), "Will Your Audience Be Right Back After These Messages?", available on-line at www.arbitron.com

[6] Arbitron Company and Edison Media Research (2003), "The National In-Car Study: Fighting for the Front Seat", available on-line at www.arbitron.com

[7] Arbitron Company (2003), "Radio Market Report. Audience Estimates in the New England County Metropolitan Area, ADI and TSA for Boston: Fall 2002 Issue", New York, NY: Arbitron Company

[8] Augereau, Angelique, Shane Greenstein and Marc Rysman (2006), "Coordination vs. Differentiation in a Standards War: 56K Modems", RAND Journal of Economics, 37(4), 887-909

[9] Bajari, Patrick, Han Hong and Stephen Ryan (2007a), "Identification and Estimation of Discrete Games of Complete Information", mimeo, University of Minnesota

[10] Bajari, Patrick, Han Hong, John Krainer and Denis Nekipelov (2007b), "Estimating Static Models of Strategic Interactions", mimeo, University of Minnesota

[11] BIA Financial Network, Inc. (2002), MediaAccess Pro version 3.0, Chantilly, VA: BIA Financial Network, Inc.

[12] Bjorn, Paul A. and Quang H. Vuong (1985), "Simultaneous Equation Models for Dummy Endogenous Variables: a Game Theoretic Formulation with an Application to Labor Force Participation", Social Science Working Paper No. 537, California Institute of Technology

[13] Bresnahan, Timothy F. and Peter C. Reiss (1991a), "Entry and Competition in Concentrated Markets", Journal of Political Economy, 99(5), 977-1009

[14] Bresnahan, Timothy F. and Peter C. Reiss (1991b), "Empirical Models of Discrete Games", Journal of Econometrics, 48(1-2), 57-81

[15] Brock, William A. and Steven N. Durlauf (2001), "Interactions-Based Models", in Handbook of Econometrics Volume 5, ed. by J.J. Heckman and E. Leamer, New York: New Holland

[16] Brock, William A. and Steven N. Durlauf (2003), "Multinomial Choice with Social Interactions", National Bureau of Economic Research Technical Paper No. 288

[17] Brock, William A. and Steven N. Durlauf (2005), "Identification of Binary Choice Models with Social Interactions", mimeo, University of Wisconsin at Madison 
[18] Brydon, Alan (1994), "Radio Must Prove Its Merit as an Advertising Medium", Campaign, 3(21), 25-6

[19] Chen, Hanfeng and Jiahua Chen (2001), "The Likelihood Ratio Test for Homogeneity in Finite Mixture Models", Canadian Journal of Statistics, 29(2), 201-215

[20] Chen, Hanfeng, Jiahua Chen and John D. Kalbfleisch (2001), "A Modified Likelihood Test for Homogeneity in Finite Mixture Models", Journal of the Royal Statistical Society Series B (Methodological), 63(1), 19-29

[21] Chen, Hanfeng, Jiahua Chen and John D. Kalbfleisch (2004), "Testing for a Finite Mixture Model with Two Components", Journal of the Royal Statistical Society Series B (Methodological), 66(1), 95-115

[22] Ciliberto, Federico and Elie Tamer (2007), "Market Structure and Multiple Equilibria in Airline Markets", mimeo, Northwestern University

[23] Dick, Steven J. and Walter McDowell (2003), "Estimating Relative Commercial Zapping Among Radio Stations Using Standard Arbitron Ratings", mimeo, University of Miami at Coral Gables

[24] Ellickson, Paul and Sanjog Misra (2007), "Supermarket Pricing Strategies", Marketing Science, forthcoming

[25] Elmore, Ryan and Shaoli Wang (2003), "Identifiability and Estimation in Multinomial Mixture Models", Pennsylvania State University, Department of Statistics Technical Report No. 03-04

[26] Epstein, Gil S. (1998), "Network Competition and the Timing of Commercials", Management Science, 44(3), 370-387

[27] Gross, Michael (1998), "Television: Some Thoughts on Flipping", Marketing and Media Decisions, 23(10), 94-6

[28] Hotz, V. Joseph and Robert A. Miller (1993), "Conditional Choice Probabilities and the Estimation of Dynamic Models", Review of Economic Studies, 60(3), 497-529

[29] Kadlec, Tomas, 2001, "Optimal Timing of TV Commercials: Symmetrical Model", CERGE-EI Working Paper No. 195, Charles University, Prague

[30] Kim, Byung Soo (1984), "Studies of Multinomial Mixture Models", unpublished PhD thesis, University of North Carolina at Chapel Hill

[31] MacFarland, David T. (1997), Future Radio Programming Strategies, $2^{\text {nd }}$ edition, Mahwah, N.J.: Erlbaum

[32] McDowell, Walter and Steven J. Dick (2003), "Switching Radio Stations While Driving: Magnitude, Motivation and Measurement Issues", Journal of Radio Studies, 10(1), 46-62

[33] McLachlan, Geoffrey J. and David Peel (2000), Finite Mixture Models, New York, NY: John Wiley

[34] Pakes, Ariel, Jack Porter, Katherine Ho and Joy Ishii (2006), "Moment Inequalities and their Application", mimeo, Harvard University

[35] Pesendorfer, Martin and Philipp Schmidt-Dengler (2007), "Asymptotic Least Squares Estimators for Dynamic Games", Review of Economic Studies, 75(3), 901-928 
[36] Rysman, Mark and Shane Greenstein (2005), "Testing for Agglomeration and Dispersion", Economics Letters, 86, 405-411

[37] Rust, John (1987), "Optimal Replacement of GMC Bus Engines: An Empirical Model of Harold Zurcher", Econometrica, 55(5), 999-1033

[38] Seim, Katja (2006), "An Empirical Model of Firm Entry with Endogenous Product-Type Choices", RAND Journal of Economics, 37(3), 619-640

[39] Sweeting, Andrew T. (2006), "Coordination, Differentiation and the Timing of Radio Commercials", Journal of Economics and Management Strategy, 15(4), 909-942

[40] Tamer, Elie T. (2003), "Incomplete Simultaneous Discrete Response Model with Multiple Equilibria", Review of Economic Studies, 70(1), 147-165

[41] Teicher, Henry (1963), "Identifiability of Finite Mixtures", Annals of Mathematical Statistics, $34(4), 1265-1269$

[42] Wang, Peiming (1994), "Mixed Regression Models for Discrete Data", unpublished PhD thesis, University of British Columbia

[43] Warren, Steve (2001), The Programming Operations Manual, San Marcos, TX: Warren Consulting

[44] Zhou, Wen (2000), "The Magnitude, Timing, and Frequency of Firm Choice: Essays on Commercial Breaks and Price Discounts", unpublished Ph.D. thesis, Duke University 